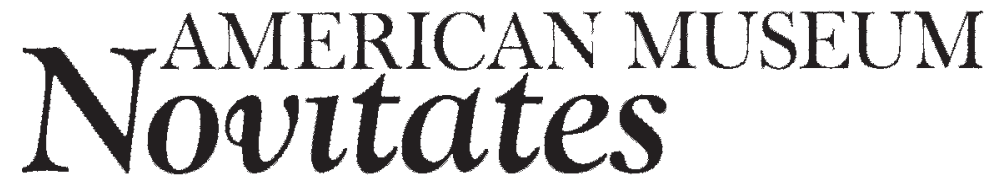

PUBLISHED BY THE AMERICAN MUSEUM OF NATURAL HISTORY CENTRAL PARK WEST AT 79TH STREET, NEW YORK, NY 10024 Number 3677, 29 pp., 10 figures, 1 table

March 4, 2010

\title{
The Braincase of Apatosaurus (Dinosauria: Sauropoda) Based on Computed Tomography of a New Specimen with Comments on Variation and Evolution in Sauropod Neuroanatomy
}

\author{
AMY M. BALANOFF, ${ }^{1,2}$ GABE S. BEVER, ${ }^{3 *}$ AND TAKEHITO IKEJIRI ${ }^{4}$
}

\begin{abstract}
We describe a previously unreported braincase of the sauropod dinosaur Apatosaurus from the Cactus Park Quarry, Morrison Formation of western Colorado using high-resolution X-ray computed tomography. The digital nature of these data allowed us to prepare and describe the first three-dimensional rendering of the endocranial space in this historically important dinosaur species. Results are compared with a range of taxa drawn from across the sauropod tree revealing previously underappreciated variation in the sauropod neurocranium. Examples of variable characters include the degree of cerebral and pontine flexure, the morphology of the parietal body and superior sagittal sinus and their relationship with the overlying dermal roof, and the conformation of several cranial nerve foramina. We provide preliminary evolutionary hypotheses and discussion for many of these features. The recognition that considerable variation is present in the sauropod neurocranium hopefully will encourage more detailed descriptions of this anatomically complex region, as well as facilitating a synthetic review of the sauropodomorph braincase as these descriptions become available.
\end{abstract}

\footnotetext{
${ }^{1}$ Division of Paleontology, American Museum of Natural History.

2 Department of Earth and Environmental Sciences, Columbia University.

${ }^{3}$ Division of Paleontology, American Museum of Natural History.

* Current address: Department of Geology and Geophysics, Yale University, 210 Whitney Avenue, New Haven, CT 06520 .

${ }^{4}$ Museum of Paleontology and Department of Geological Sciences, University of Michigan, 1109 Geddes Road, Ann Arbor, MI 48109-1079.
} 


\section{INTRODUCTION}

The complex nature of the vertebrate braincase makes this region a rich source of phylogenetically informative data. The braincase and neuroanatomy of sauropod dinosaurs, however, historically have played a relatively minor role in shaping hypotheses with regards to the phylogenetic and evolutionary history of this unique and interesting group. This relative lack of influence undoubtedly stems from the rarity with which well-preserved cranial material is recovered, with the postcranial elements traditionally considered diagnostic for refined taxonomic levels within this group (Tidwell and Carpenter, 2003; see Wilson, 2002: table 8). This preservational gap translates directly to the existing disparity in our understanding of morphological variation for these respective anatomical systems across Sauropoda and reinforces the need for detailed anatomical description and comparison of whatever cranial data are available. One way to increase the return of anatomical data from a particular specimen is through the use of high-resolution $\mathrm{X}$-ray computed tomography (HRCT). HRCT is a nondestructive tool for visualizing internal structures and is particularly useful for studying the complex internal anatomy of a fossilized braincase (Carlson et al., 2003). In addition to providing access to internal cranial features such as the presence/absence of bony contacts and processes, HRCT enhances our ability to visualize and interpret soft-tissue structures of the central nervous, circulatory, and endocrine systems that are housed within the braincase.

The purpose of this study is to provide a detailed description of a previously unreported braincase of Apatosaurus that includes the first observations on the internal braincase anatomy of this taxon. Observed morphologies are compared with selected sauropod and outgroup taxa allowing preliminary assessments of neurocranial variation and evolution within Sauropoda. We review the published literature and explicitly establish baseline evolutionary hypotheses for a number of selected neurocranial features within Sauropoda. The hope is that these hypotheses will elicit future testing and provide the groundwork for more synthetic studies examining broad patterns of neurocranial evolution within Sauropodomorpha.
Institutional abbreviations used in this study: AMNH (American Museum of Natural History, New York, New York); BYU (Brigham Young University, Earth Science Museum, Provo, Utah); CM (Carnegie Museum of Natural History, Pittsburgh, Pennsylvania); HMS (Houston Museum of Natural Science, Houston, Texas); YPM (Yale University, Peabody Museum of Natural History, New Haven, Connecticut).

\section{MATERIALS AND METHODS}

\section{SPECIMEN}

We describe a fairly complete, well-preserved braincase of Apatosaurus (BYU 17096; figs. 1, 2), using HRCT. BYU 17096 was collected from the Jurassic Morrison Formation of the Cactus Park BYU Quarry in western Colorado. The endocranial space is completely infilled with a fine-grained sandstone matrix. The allocation of BYU 17096 to Apatosaurus is based in part on the hundreds of disarticulated and semiarticulated postcranial bones diagnosable to Apatosaurus (especially cervicals, dorsals, anterior caudals, and relatively robust limb bones) that were found in the same quarry (Curtice and Wilhite, 1996; Foster, 2003). None of the other genera common in the Morrison Formation, such as Diplodocus and Camarasaurus, were recovered from the Cactus Park Quarry. The diagnosis of BYU 17096 to Apatosaurus also is based on observed braincase apomorphies discussed in the Phylogenetic Diagnosis section below.

\section{SCANNING}

BYU 17096 was scanned at the University of Texas High-Resolution X-ray Computed Tomography Facility on 14 May 2004 using their high-energy system. Scanning was performed using a brass filter and air wedge, a voltage of $420 \mathrm{kV}$, and an amperage of $4.8 \mathrm{~mA}$. The resulting images were then processed for the removal of ring and streak artifacts using programs written by Richard Ketcham. The specimen was scanned along the coronal axis for a total of 127 slices at an image resolution of $1024 \times 1024$ pixels. The interslice spacing is $1.0 \mathrm{~mm}$, and the slice thickness is $0.8 \mathrm{~mm}$. Each image has a reconstructed field of view of 
$265 \mathrm{~mm}$. The reconstruction of the endocranial endocast was done with the original 16-bit imagery in the volumetric rendering program VGStudioMax॰ 1.2.1. Contrast of the images was increased until the infilled endocranial space and bone were easily distinguishable from each other. The endocranial cavity was selected using the segmentation tools available in this program, separated into its own volume, and exported as an isosurface. All measurements of the braincase and endocast (including volume) were taken in VGStudioMax॰. Endocast volume measurements were taken by calculating the volume of negative space of the endocranial cavity. For ease of description, features of the endocranial cast are referred to by the names of the soft tissues of the brain that they reflect (e.g., cerebrum rather than cast of cerebrum). It is important to note, however, that what actually is preserved is a cast of the endocranial space, which also reflects structures other than the brain, such as meninges and sinuses. This cast, however, is useful in determining relative size and shape of different regions of the brain as well as recognizing the morphology of the cranial nerve roots. The original slice data and movies showing the endocranial cast are available at the DigiMorph website (www. digimorph.org/specimens/Apatosaurus_sp).

\section{TAXonOMIC COMPARISONS}

The inclusion of cranial material into phylogenetic analyses of sauropods (e.g., Wilson, 2002; Upchurch et al., 2004; Rauhut et al., 2005) makes the diagnosis of newly discovered material more confident. Previous descriptions of cranial material allocated to Apatosaurus include that of Berman and McIntosh (1978), who described a fairly complete skull (CM 11162) of a "probable" Apatosaurus (Berman and McIntosh, 1998: 21) and a partial braincase (YPM 1860) from the upper Jurassic Morrison Formation of Colorado. A partly disarticulated braincase is known from Como Bluff, Wyoming (Connely and Hawley, 1998). In addition to describing a new braincase of Apatosaurus, we present the only endocast that is known for this taxon.

The number of endocasts that exist for sauropodomorph taxa is surprisingly large, although the majority of these were only briefly described and illustrated in the late 19th and early 20th centuries (Marsh, 1880, 1884; Holland, 1906; Osborn and Mook, 1921; Ostrom and McIntosh, 1966). An endocast of Diplodocus (AMNH 694) was described by Marsh (1884, 1896) and reillustrated by Hopson (1979). Janensch (1935-36) described an endocast of Brachiosaurus as well as two diplodocoid taxa, Dicraeosaurus and Tornieria (Tornieria is referred to as Barosaurus in Janensch [1935-36]; however, see Remes [2006] for updated taxonomy). Many of the more recent descriptions are based on synthetic endocasts. These include Plateosaurus (Galton, 1985), Shunosaurus (Chatterjee and Zheng, 2002), an early Cretaceous titanosauriform (TMM 40435; Tidwell and Carpenter, 2003), and Camarasaurus (Chatterjee and Zheng, 2005; Sereno et al., 2007). A digital endocast was extracted from HMS 175 and described as Diplodocus hayi (Franzosa, 2004), although the allocation of this specimen to Diplodocus is questionable (see Harris, 2006). Comparative illustrations of a digital endocast of Diplodocus also are available in Sereno et al. (2007).

\section{DESCRIPTION}

\section{General Features}

Figures 1, 2

BYU 17096 is an articulated braincase that is complete in that it includes the right and left orbitosphenoid, laterosphenoid, exoccipitalopisthotic, prootic, and the midline basisphenoid, basioccipital, and supraoccipital. The paired frontal, parietal, squamosal, and postorbital also are present as components of the dermal roof fused to the endochondral elements of the braincase. The braincase is well preserved overall, although the distal extremities of several bones and processes are broken. The dermal roofing components are better preserved on the right side of the skull. The specimen is large overall (see table 1) and the cranial sutures are so tightly fused as to be indistinguishable in many cases in external view (as is common in sauropods; e.g., Tidwell and Carpenter [2003], Wilson et al. [2005], Remes [2006]). This advanced state of fusion is present in both the dermal roofing and endochondral elements, indicating skeletal 


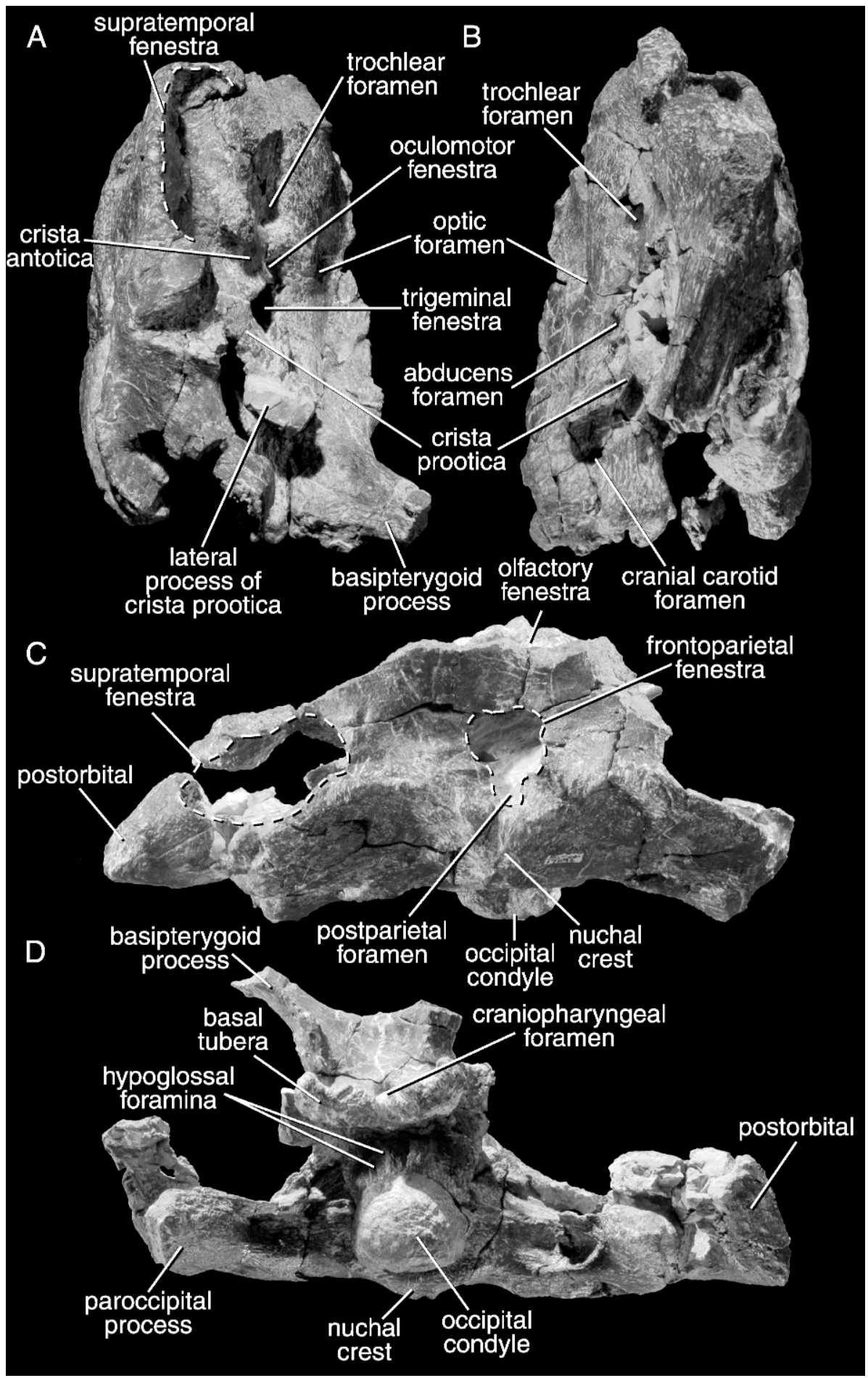

Fig. 1. Braincase of BYU 17096 in right lateral (A), left lateral (B), dorsal (C), and ventral (D) views. 


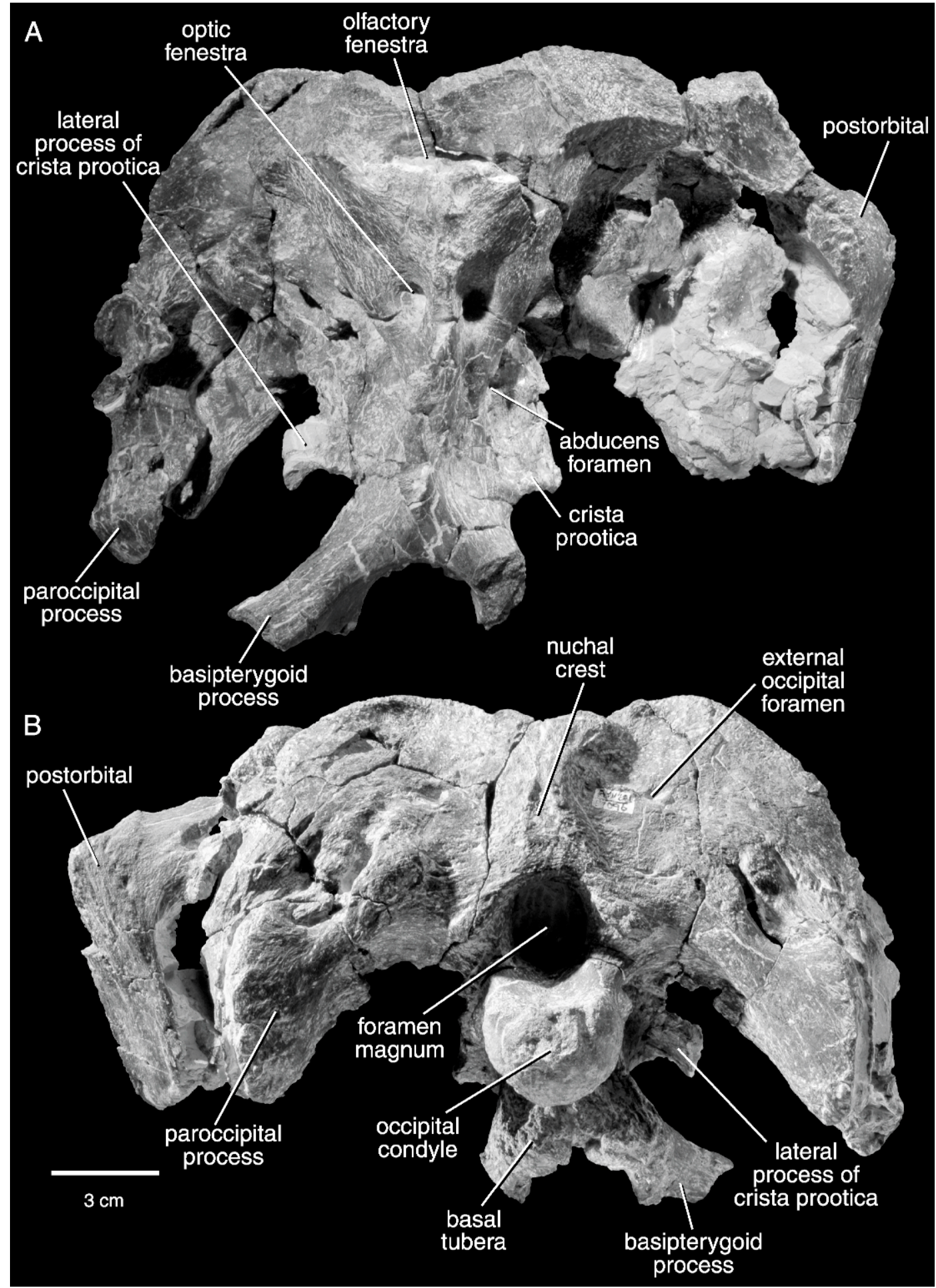

Fig. 2. Braincase of BYU 17096 in anterior (A) and posterior (B) views. 
TABLE 1

Measurements taken from BYU 17096

All measurements are in $\mathrm{mm}$.

\begin{tabular}{lr}
\hline \hline Transverse width of parietals & 169.6 \\
Anteroposterior length of parietals & 30.2 \\
Dorsoventral height of supraoccipital & 52.0 \\
Transverse width of supraoccipital & 60.8 \\
Transverse width of foramen magnum & 24.6 \\
Dorsoventral height of foramen magnum & 27.6 \\
Anteroposterior width of supratemporal fenestra & 21.2 \\
Transverse length of supratemporal fenestra & 39.7 \\
Anteroposterior length of frontoparietal fenestra & 33.6 \\
Transverse width of frontoparietal fenestra & 25.6 \\
Anteroposterior length of skull & 94.0 \\
Transverse width of skull across metotic foramina & 31.5 \\
Transverse width of skull across paroccipital & \\
$\quad$ processes & 169.2 \\
Anteroposterior length of endocast & 72.5 \\
Transverse width of endocast at widest point & 49.4 \\
\hline
\end{tabular}

maturity for these cranial partitions (but not necessarily indicative of sexual maturation or maturation of other skeletal regions). The HRCT slices did help considerably in locating at least some of these sutures by revealing their location deep to the external surface (fig. 3). Their three-dimensional paths could then be traced superficially to the external surface of the specimen. Our ability to do this indicates that the degree of fusion is not uniform along the three-dimensional path of these sutures and that cranial fusion often occurs first at the external surface of the skull and progresses deeper.

\section{Dermal Roof}

Frontoparietal Fenestra: The dorsal surface of BYU 17096 is formed largely by the dermal roofing elements, which overlie the anterior two-thirds of the endocranial cavity. The dorsal surface is slightly concave up in overall shape and is dominated by a large central opening that lies at the junction of the paired frontals and parietals. This opening constitutes a broad communication (table 1) between the external space dorsal to the cranial roof and the endocranial cavity. This communication often is referred to as the parietal foramen (e.g., Salgado and Calvo, 1992; Chatterjee and Zheng, 2002), presumably because of an inferred homology with the parietal foramen that houses the pineal body in other reptiles (Janensch, 1935-36; Edinger, 1955).
Hopson (1979) noted this opening may not represent the parietal foramen but rather was possibly filled with part of the cartilaginous endocranium or with a portion of the superior sagittal sinus (or a combination of the dorsal longitudinal and transverse sinuses; Witmer and Ridgely, 2009). The opening in BYU 17096 is confluent with the superior sagittal sinus that otherwise is enclosed within the paired parietals (see description of endocast below). The opening also resides at a position homologous to the frontoparietal fontanelle of amniote embryos. Therefore, it is possible that an anterodorsal expansion of the superior sagittal sinus into the space between the developing elements of the dermal roof influenced the developmental dynamics of that region and thus resulted in the paedomorphic retention of the frontoparietal fontanelle in the adult skull as the frontoparietal fenestra.

The shape of the frontoparietal fenestra in BYU 17096 is not perfectly circular but rather exhibits a brief constriction near its posterior margin due to a slight medially directed curvature of the parietals (fig. 1C). This constriction results in an incomplete partitioning of the fenestra into a relatively large anterior section and a much smaller posterior opening. This partitioning suggests that the frontoparietal fenestra may have housed two separate softbodied structures (positioned anteriorly and posteriorly, respectively). The anterior component may have housed the parietal (pineal) body, with a dorsal peak of the superior sagittal sinus filling the posterior partition (see Witmer and Ridgely, 2009). This medial constriction of the parietals and associated partitioning of the frontoparietal fenestra is common in sauropods that exhibit this dorsal opening, and a complete division of the fenestra through medial contact of the parietals is known within this group (e.g., Amargasaurus cazaui; Salgado and Calvo, 1992; Salgado, 1999). This posterior opening generally is described as the postparietal foramen (Janensch, 1935-36; Salgado and Calvo, 1992; Salgado, 1999), which was an unambiguous synapomorphy of Dicraeosauridae (Wilson, 2002) but may be derived for the more inclusive Flagellicaudata (Harris and Dodson, 2004; Harris, 2006).

FrontALs: The frontals are wedge-shaped bones in dorsal view whose posterior margin is 

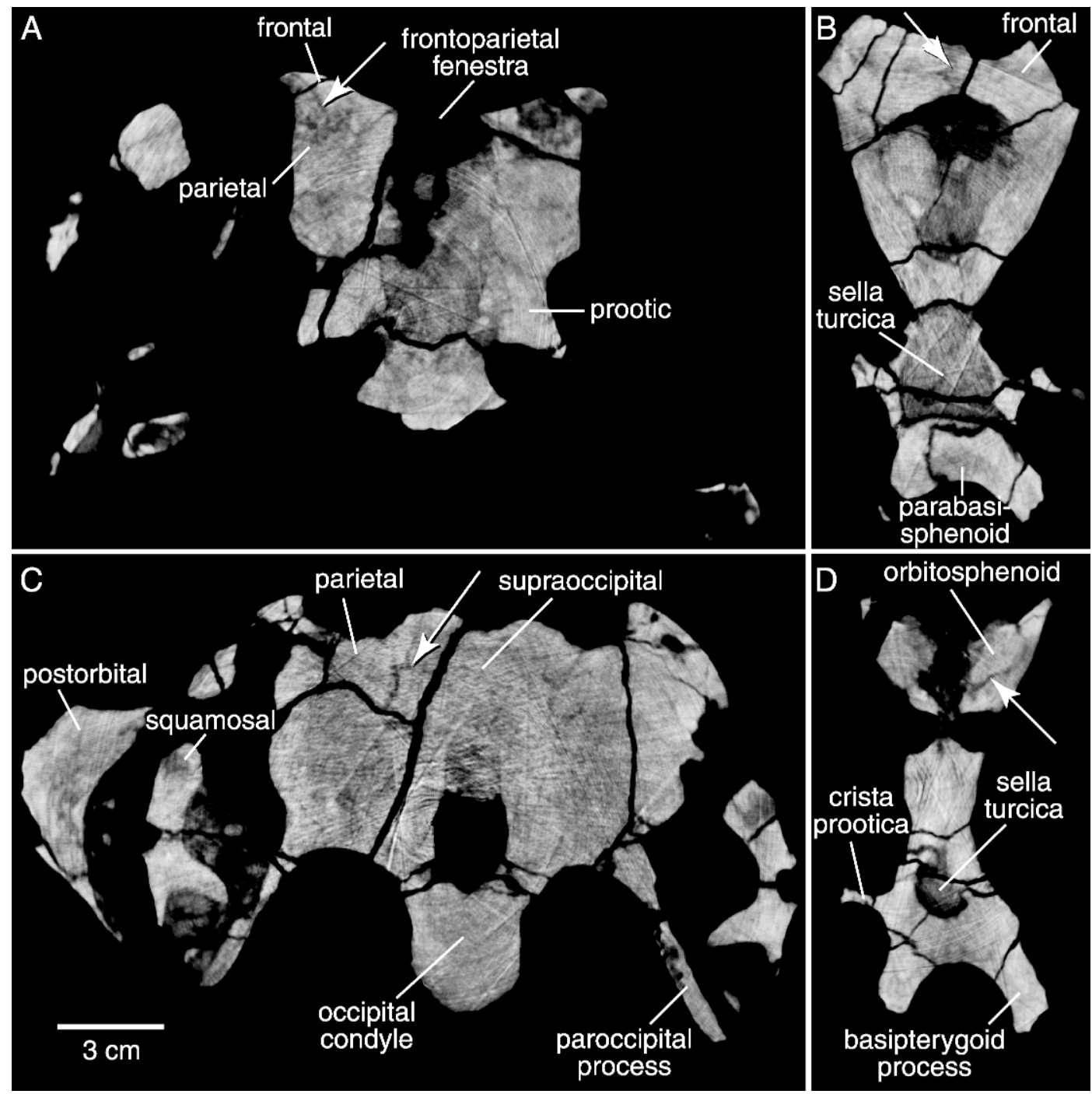

Fig. 3. Two-dimensional HRCT slices through the coronal plane of BYU 17096. Arrows denote the frontal-parietal suture (A), frontal-frontal suture (B), parietal-supraoccipital suture (C), and orbitosphenoidlaterosphenoid suture (D).

tapered due to the presence of the frontoparietal fenestra to which they contribute (along with the parietals; fig. 1C). The frontals are relatively shorter anteroposteriorly with their length being less than twice their transverse breadth (Wilson, 2002). The frontals contact the orbitosphenoid and laterosphenoid ventrolaterally, parietal posteriorly, postorbital posterolaterally, and each other medially. The frontal-parietal suture, which is clearly visible in the HRCT slices (fig. 3A), begins lateral to the frontoparietal fenestra and extends to the supratemporal fenestra along a slightly sinuous trajectory. This suture turns anteriorly and somewhat ventrally at the lateral edge of the braincase resulting in the dorsal surface of the postorbital process being comprised entirely by the frontal (the lateral ends of this suture lie completely rostral to the supratemporal fenestra unlike Suuwassea; Harris, 2006). The frontal-parietal contact lies near the suture between the laterosphenoid and 


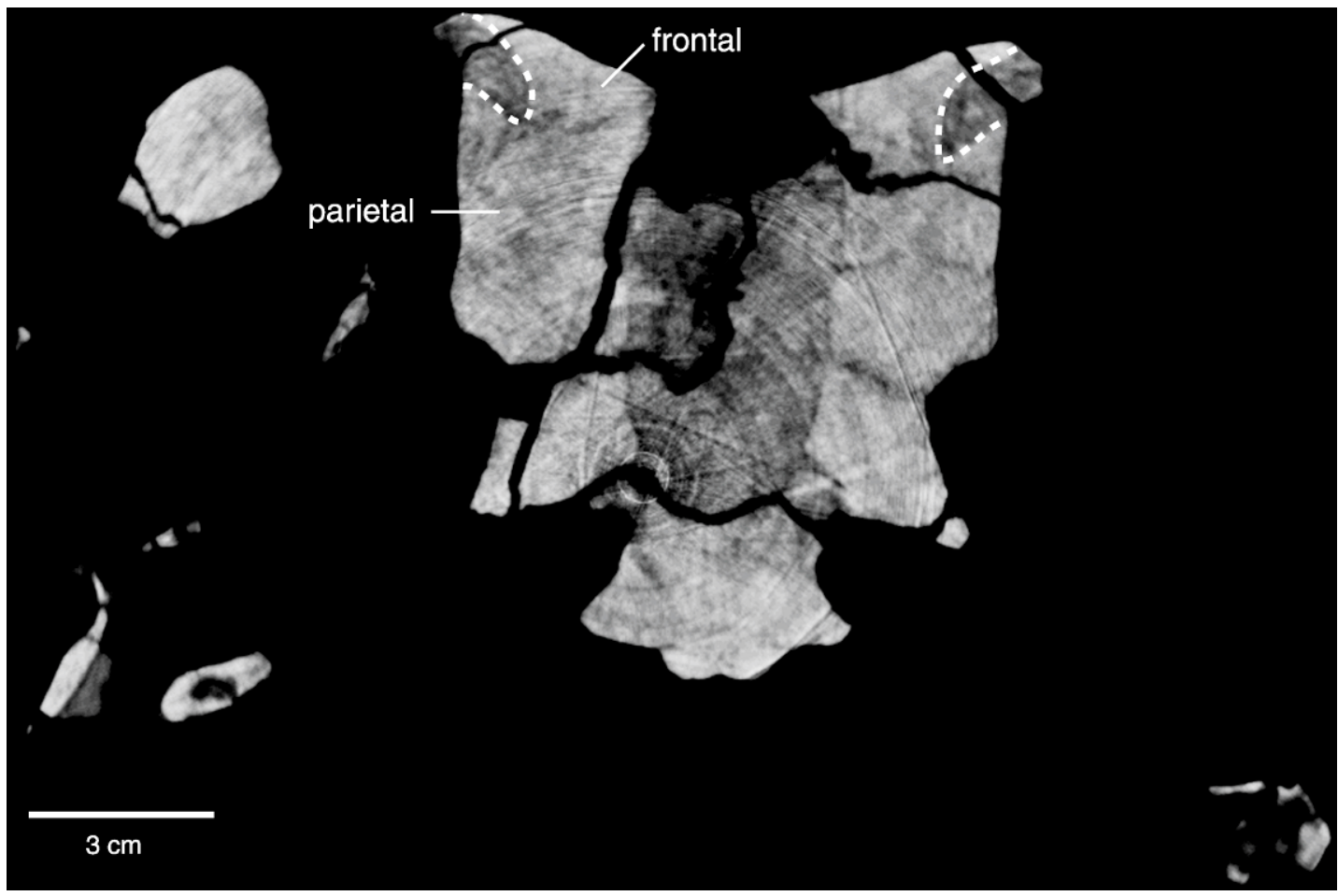

Fig. 4. Two-dimensional HRCT slice through a coronal plane of the braincase of BYU 17096. Dotted line delineates a paired fossa formed within the frontals.

prootic (as in most sauropods; Wilson et al., 2005). The frontal-parietal suture is overlapping for much of its breadth (with the frontals overlying the parietals) before pinching out posterolaterally (fig. 3A). The frontal-frontal suture is present and, as revealed in the CT slices, distinctly interdigitating (fig. 3B). This medial contact is sutured but not fully fused as in dicraeosaurids (Salgado and Calvo, 1992; Wilson, 2002) and possibly Tornieria (Harris, 2006). The frontals form the dorsal margin of the large anterior fenestra for the olfactory tracts (see Orbitosphenoid below). A pair of bilaterally symmetrical fossae, whose origin is unclear, penetrates the lateral margin of the frontals from within the supratemporal fenestra (fig. 4). These fossae extend ventromedially within the frontals before terminating at or near the frontal-parietal suture lateral to the frontoparietal fenestra. The frontals fail to contribute to the supratemporal fossa (Wilson, 2002).

PARIETAls: The parietals are smaller than the frontals. The parietals contact the frontals anteriorly, postorbital anterolaterally, parietal and squamosal posterolaterally, prootic anteroventrally, exoccipital-opisthotic posteroventrally, and supraoccipital posteriorly. Their median contact is negated by the diameter of the frontoparietal fenestra, whose posterior margin is formed by the supraoccipital (see below). The medial margins of the parietals do extend a short distance towards the cranial midline thereby constricting (slightly) the frontoparietal fenestra. The parietal along with the postorbital contributes to the supratemporal fenestra, which is wider than long (table 1) and preserved only on the left side of the skull. The diameter of the supratemporal fenestra (in either direction) is distinctly larger than that of the foramen magnum (table 1; Wilson, 2002). The distance separating the right and left supratemporal fenestrae is greater than the largest diameter of the supratemporal fenestra (Wilson, 2002). The supratemporal fenestra faces more laterally than dorsally (as in Apatosaurus and Suuwassea; Harris, 2006). The parietals of BYU 
17096 contain low arcuate ridges on either side of the supraoccipital that mark the posterior margin of the skull (Wilson et al., 2005). The parietals overlap the supraoccipital and extend laterally to overlay the exoccipital-opisthotic. The parietal-exoccipital suture is sinuous as described for Apatosaurus (Berman and McIntosh, 1978) and Tornieria (Remes, 2006) and unlike the linear suture of Suuwassea (Harris, 2006). A squamosal-supraoccipital contact excludes a parietal participation in the dorsal margin of the posttemporal fenestra (a diplodocoid synapomorphy; Calvo and Salgado, 1995; Upchurch, 1998; Remes, 2006). The occipital process of the parietal is deep, being approximately twice the diameter of the foramen magnum (Wilson, 2002).

Postorbitals: The left postorbital is more completely preserved than the right (fig. 1B, C). The postorbital contacts the frontal anteromedially, parietal dorsomedially, and squamosal medially. The postorbital contributes to the formation of the supratemporal fenestra through its significant contribution to the postorbital process where it contacts the frontal along its medial surface. The distal ends of both the jugal and squamosal processes are broken resulting in the postorbital lacking the triradiate shape present in Apatosaurus and other sauropods (Berman and McIntosh, 1978). The preserved lengths of these processes both indicate that they were broader transversely than anteroposteriorly (Wilson, 2002). The postorbital does possess a distinct but short posterior process (Wilson, 2002). The temporal bar is longer anteroposteriorly than transversely, and is shifted ventrally exposing the supratemporal fossa in lateral view (Wilson, 2002).

SQuamosals: The right and left squamosals are present and contact the parietal medially, postorbital laterally, and exoccipital-opisthotic posteromedially. The squamosal lies in the posterolateral corner of the skull directly anterior to the paroccipital process of the exocccipital-opisthotic (structure to which the squamosal is firmly fused). The squamosal contacts the lateral margin of the parietal along a relatively complex suture that includes both overlapping (with the squamosal overlapping the parietal) and interdigitating regions.

\section{BRAINCASE}

SuPraOCCIPITAL: The supraoccipital is a midline ossification that roofs the posterior portion of the endocranial cavity. The supraoccipital contacts the parietals anterodorsally and laterally, and the exoccipital-opisthotic ventrolaterally. In dorsal view, the supraoccipital underlies the paired parietals along its lateral margins and forms the posterior margin of the frontoparietal fenestra (fig. 2B). The anterodorsal margin of the supraoccipital that borders the frontoparietal fenestra is slightly concave in posterior view (fig. 1C). The anterior surface of the supraoccipital that forms the caudal wall of the posterior portion of the frontoparietal fenestra is concave, forming a vertical groove that would have housed a dorsal extension of the dural venous sinus system.

The occiput overall is flat to slightly concave (posteriorly) and therefore lacks the convex "supraoccipital wedge" described in some sauropod braincases (fig. 2B; e.g., eusauropod from India; Wilson et al., 2005). In posterior view, the occiput is rectangular in shape and compares closely with the high and vaulted occiput described for Apatosaurus (Berman and McIntosh, 1978). The height of the supraoccipital in posterior view is greater than twice the height of the foramen magnum, which appears to be the plesiomorphic condition for sauropods (Wilson, 2002). A distinct nuchal crest extends along the midline of the supraoccipital beginning at the posterior margin of the frontoparietal fenestra and ending at or just above the dorsal margin of the foramen magnum. A nuchal fossa lies lateral to the nuchal crest on either side in the posterior occipital plate.

The supraoccipital forms a contact with the exoccipital-opisthotic that begins laterally, just dorsal to the base of the paroccipital process, and curves ventromedially to reach the dorsolateral margin of the foramen magnum. The angle of this ventromedial curvature is steeper in BYU 17096 than in YPM 1860 (Berman and McIntosh, 1978). The supraoccipital forms the dorsal margin of the circular foramen magnum (slight mediolateral compression). The external occipital fenestra lies dorsal and lateral to the foramen magnum and is clearly visible in posterior view (fig. 2B). 


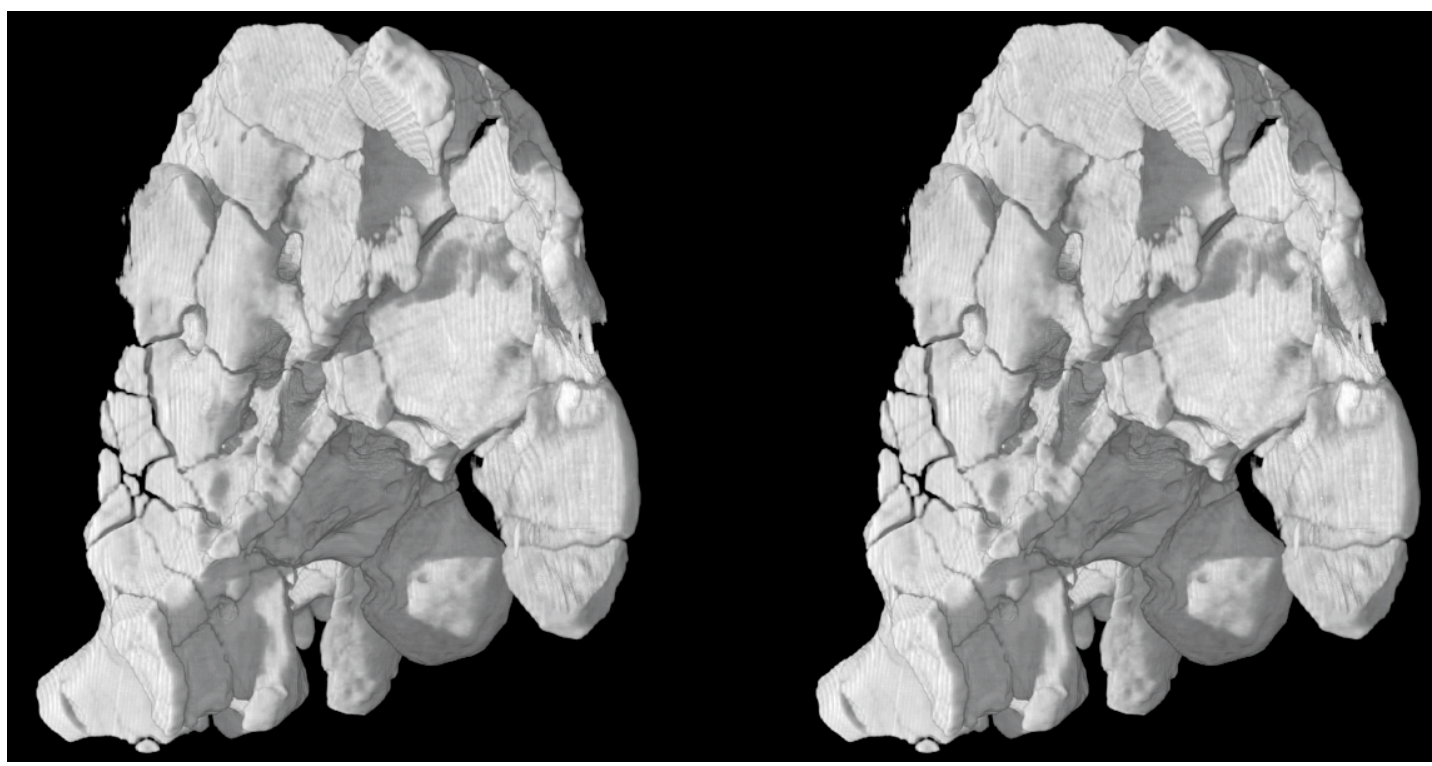

Fig. 5. Stereo rendering of the braincase of BYU 17096 in ventrolateral view. The squamosal and postorbital have been digitally removed from the braincase.

This fenestra pierces the occipital plate at the supraoccipital-parietal suture, where it would have transmitted the external occipital vein (caudal middle cerebral vein; Witmer and Ridgely, 2009) out of the endocranial cavity and onto the external surface of the occipital plate. The external path of this vein is marked by a distinct groove that runs ventrolaterally from the external occipital fenestra, following the general trajectory of the supraoccipitalparietal suture (this external groove often is present in birds; Baumel and Witmer, 1993).

ExосcIPITAL-Opisthotic: The exoccipital and opisthotic are fused completely and therefore described as a single complex. The exoccipital-opisthotic contacts the parietal dorsally, supraoccipital medially, prootic and squamosal anteriorly, basioccipital posteroventrally, and basisphenoid anteroventrally. The exoccipital-opisthotic contributes to the lateral and ventral margins of the foramen magnum. The suture with the overlying supraoccipital is visible and positioned near the dorsoventral midline of the foramen magnum. A distinct prominence lies lateral to the foramen magnum and encompasses portions of both the supraoccipital and exoccipital-opisthotic. It is unclear whether this structure represents a proatlantal facet, which is rare in sauropods (Wilson et al., 2005).

The ventral suture with the basioccipital cannot be discerned so it is unclear to what degree the exoccipital contributes to the massive occipital condyle and whether the basioccipital is completely excluded from the ventral margin of the foramen magnum. The exoccipitals do form a large proportion of the occipital condyle in YPM 1860 and completely exclude the basioccipital from the ventral margin of the foramen magnum (Berman and McIntosh, 1978). In most sauropods where the relative contribution can be discerned (e.g., Shunosaurus; Chatterjee and Zheng, 2002), the basioccipital forms the majority of the occipital condyle. The occipital condyle of BYU 17096 as a whole is hemispherical in shape with a dorsal surface that is concave up, differing from Diplodocus that has a rounded dorsal margin (Berman and McIntosh, 1978). The pedunculate occipital condyle is deflected posteroventrally, projecting from the main body of the basicranium at an angle of approximately $80^{\circ}$ from the horizontal plane of the skull roof.

The exoccipital-opisthotic forms a prominent paroccipital process that extends ventrolaterally to contact the squamosal. Rather than extending at a distinct posterolateral 


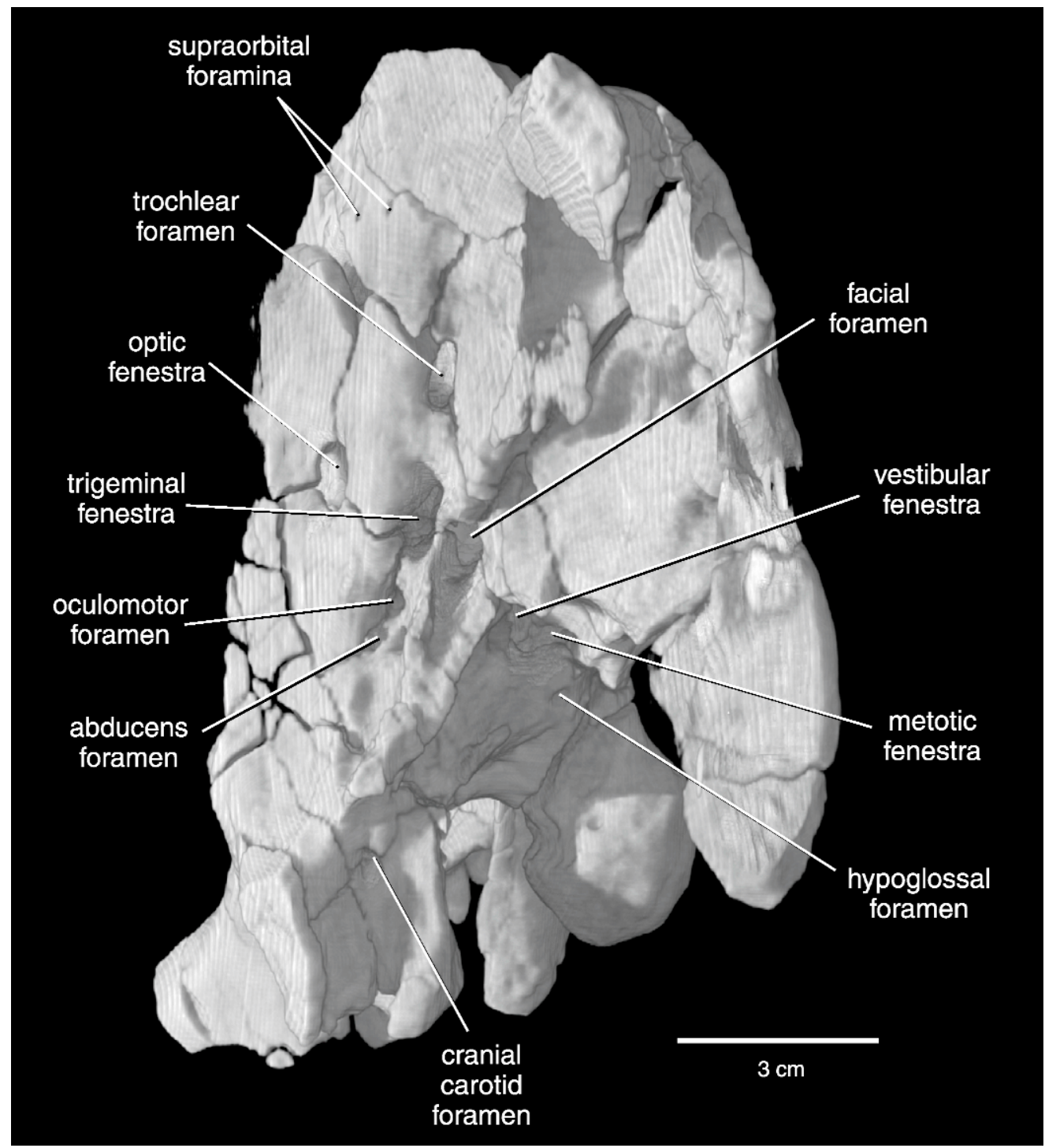

Fig. 5. Continued. Three-dimensional volume rendering of the braincase of BYU 17096 in ventrolateral view showing the spatial distribution of the major braincase foramina. The squamosal and postorbital have been digitally removed from the braincase.

orientation, these processes lie approximately in the same coronal plane as the flattened occipital plate (a diagnostic character of Eusauropoda; Wilson, 2002). The shaft of the paroccipital process is thin relative to its distal end, which widens distinctly where it meets the squamosal along a broad, flat contact that is oriented dorsoventrally. The shaft of the paroccipital process in BYU 17096 forms the ventral margin of the posttemporal foramen and lacks a ventral nonarticular process (as scored for Apatosaurus by Wilson, 2002).

A large foramen pierces the lateral surface of the braincase at a position posterior to, and slightly below, the trigeminal fenestra. The fenestra is delineated by the prootic anteriorly, exoccipital-opisthotic dorsally, and basioccipital ventrally (fig. 5). A slight dorsoventral constriction at midlength partly divides the opening into anterior and posterior compo- 
nents. The anterior component is the fenestra vestibuli and would have accepted the columella auris. The posterior component is the postnatal remnant of the metotic fissure (here referred to as the cavum metoticum) and would have housed the jugular vein, cranial nerves IX-XI, and the distal end of the perilymphatic duct. The cavum metoticum is thus undivided in the traditional sense (De Beer, 1937; Rieppel, 1985) and its lateral opening is referred to as the metotic fenestra following the majority of sauropod workers (jugular foramen of White, 1958; Madsen et al., 1995; see below). The extensive confluence between the vestibular fenestra and the metotic fenestra results from the lateral margin of the crista interfenestralis being either broken away or unossified. The bilateral symmetry of this morphology supports a late postnatal ossification of this margin in BYU 17096. The absence of this margin exposes the foramen perilymphaticum, which opens posteroventrally into the cavum metoticum. The metotic fenestra lacks the foramen lacerum posterior described in Thecodontosaurus antiquus (Benton et al., 2000). Directly caudal to the metotic fenestra on the posterolateral surface of the left exoccipital-opisthotic is a relatively small foramen. The foramen leads into a canal that extends posteromedially before opening into the posterolateral floor of the endocranial space. We interpret this foramen as a third hypoglossal foramen that is not present on the right side. A pair of bilaterally symmetrical hypoglossal (XII) foramina is positioned posterior and ventral to the metotic fenestra near the base of the peduncle of the occipital condyle. We interpret these hypoglossal canals as lying completely within the basioccipital, although it is difficult to discern whether the external foramina lie completely within the basioccipital or between the basioccipital and exoccipital-opisthotic. The asymmetric third hypoglossal canal exits the endocranial space through the basioccipital but exits the skull through the exoccipital-opisthotic.

The extremely close proximity of the third hypoglossal foramen to the metotic fenestra in BYU 17096 forces the consideration that it may represent a division of the cavum metoticum, and instead of housing a third branch of XII, it would have transmitted one or more of the structures that plesiomorphically traverse that space. One possibility under this scenario would be that the opening referred to here as the metotic fenestra is the fenestra pseudorotundum of birds and crocodiles, which is the lateral opening of the recessus scalae tympani (i.e., the anterior division of the cavum metoticum) and therefore would have housed the extracapsular length of the perilymphatic duct and possibly the glossopharyngeal (IX) nerve (Currie, 1997). This would make the small posterior foramen the jugular foramen, which is the external opening of the posterior division of the cavum metoticum that transmits the jugular vein, vagus (X) and accessory (XI) nerves. The small size of this foramen seems to preclude the possibility that it transmitted all of these structures. It might be possible that this small asymmetric foramen reflects an internal ramification of the vagal complex such that the accessory (XI) nerve ends up with its own bony canal. If this is the case, the cavum metoticum still is not divided in the traditional sense and the lateral opening should be referred to as the metotic fenestra. If this foramen did transmit the accessory nerve, then its medial confluence with the endocranial space would be expected to lie directly behind the point of exit of cranial nerve $X$ rather than adjacent to the foramen magnum (which is where it is located). The asymmetry of this feature also suggests that it is more likely to have housed a branch of the hypoglossal nerve, as intraspecific variation in the number and symmetry of hypoglossal foramina is well documented in extant reptiles (Bellairs and Kamal, 1981).

BASIOCCIPITAL: The basioccipital floors the posterior half of the endocranial cavity including the rhombencephalon portion of the hindbrain (fig. 1D). The basioccipital contacts the parabasisphenoid anteriorly, prootic anterodorsally, and exoccipital-opisthotic posterodorsally. As noted above, the basioccipital participates in the fenestra pseudorotundum, metotic fenestra, and hypoglossal foramina and contributes to the ventral portion of the occipital condyle.

A pair of prominent and robust basal tubera projects from the basicranium as ventrolateral extensions of the basioccipital 
(fig. 1D). These tubera do not appear to receive a contribution from the parabasisphenoid as described in some sauropods (e.g., Wilson et al., 2005). The anteroposterior depth of each tuber is approximately one-half the dorsoventral height of the process. The basal tubera are separated from the more anteriorly positioned basipterygoid processes of the parabasisphenoid by a low rounded ridge, the crista ventrolateralis, which delineates a shallow recess (in lateral view). This recess results in the basal tubera being separated from the basipterygoid processes rather than closely associated and forming a single large complex (e.g., Tornieria; Remes, 2006). There is no distinct depression between the foramen magnum and the basal tubera.

PARABASISPHENOID: The parabasisphenoid contacts the laterosphenoid and prootic dorsolaterally, basioccipital posteriorly, and the exoccipital-opisthotic posterodorsally. There is no evidence of a contact between the parabasisphenoid and the missing quadrates, which is a derived condition in some sauropods (Wilson, 2002). The parabasisphenoid contributes to the posterior margin of the oculomotor (III) foramen on the lateral surface of the braincase (fig. 5; see laterosphenoid below). The external abducens foramen lies just ventral to the oculomoter foramen and is approximately the same size as this opening (see Discussion). The inferior opening of the craniopharyngeal canal is present as a foramen on the ventral surface of the parabasisphenoid along its sagittal midline (see Endocranial Cast below).

The distal end of both the right and left basipterygoid process is broken with the right process more completely preserved. The preserved proportions of these processes compare closely with those of YPM 1860 (Berman and McIntosh, 1978), suggesting that their length was at least four times greater than the diameter of their base. The basipterygoid processes extend anterolaterally (a diplodocoid synapomorphy; fig. 1D; Calvo and Salgado, 1995; Upchurch, 1998; Wilson, 2002; Remes, 2006) and are separated from each other by an angle of approximately $60^{\circ}-70^{\circ}$. This angle was somewhat difficult to assess due to some potential postmortem distortion. Between these processes lies a distinct recess, but there is no evidence of a medial, rounded shelf as described for YPM 1860 (Berman and McIntosh, 1978). A shallow groove in the external surface of the basipterygoid process marks the path of the internal carotid artery as it approaches the internal carotid foramen, which is positioned laterally near the base of the process (see Endocranial Cast below). The mediolaterally flattened cultriform process is broken.

ORBITOSPHENOID: The paired orbitosphenoids form the dorsolateral walls of the rostral end of the endocranial cavity (fig. 2A). These bones are oriented largely along a transverse plane. The orbitosphenoids contact each other anteromedially, the frontals dorsolaterally, laterosphenoid posterolaterally, and parabasisphenoid ventrally. The orbitosphenoid forms the lateral and ventral margin of the large median opening that transmits the olfactory tracts into the endocranial cavity (the roof of this opening is formed by the frontals). Ventral and slightly anterior to the olfactory fenestra, the orbitosphenoids make a small contribution to the anterior margin of the optic foramina (see Laterosphenoid below).

Prootic: The prootic (fig. 1A, B) is a large, paired element that contacts the laterosphenoid anteriorly, parietal dorsally, parabasisphenoid anteroventrally, basioccipital posteroventrally, and exoccipital-opisthotic posteriorly. The dorsal suture between the prootic anteriorly and the opisthotic posteriorly is difficult to discern but can be approximated based on the position of the anteroposteriorly elongate fenestra vestibuli. The prootic does not contribute to the metotic fenestra, as described for a eusauropod braincase (metotic foramen of Wilson et al., 2005). The prootic forms the posterior margin of the trochlear (IV) and trigeminal (V) foramina (see Laterosphenoid). A relatively small foramen transmitting the facial (VII) nerve out of the endocranial space penetrates the prootic posterior to the trigeminal fenestra and directly anterodorsal to the metotic fenestra. The facial foramen is visible only on the right side.

A crista prootica extends posterodorsally along the lateral surface of the prootic separating the vestibular fenestra (posteriorly) from the facial foramen (anteriorly; the facial foramen lies nearly within the crista prootica). The crista, which is better preserved on the right side, is strongly developed and heavily 
compressed along its long axis. A crista antotica, which is much less developed than the crista prootica, also is present and separates the facial foramen from the foramina transmitting cranial nerves III-V (fig. 5). This crista begins on the prootic and extends onto the laterosphenoid (see below).

LATEROSPHENOID: The paired laterosphenoid is a platelike bone that helps to enclose the anterolateral portion of the endocranial space (see Clark et al., 1993). The laterosphenoid contacts the orbitosphenoid anteromedially, frontal dorsally, parabasisphenoid ventrally, and prootic posteriorly. The laterosphenoid-orbitosphenoid suture is overlapping for most of its length (with the laterosphenoid positioned lateral to the orbitosphenoid). The suture between these elements is clearly visible anteriorly in the HRCT slices (fig. 3D) but becomes obscured in the coronal slices posteriorly. A facet marking the point of contact with the epipterygoid is present (Wilson, 2002).

The laterosphenoid forms the majority of the large optic fenestra, which transmits the optic (II) nerve into the orbital cavity. (There is also a small contribution from the orbitosphenoid, see above.) The laterosphenoid contributes the anterior margin of the oculomotor (III), trochlear (IV), and trigeminal (V) foramina. The large trigeminal fenestra is positioned posterior to the optic fenestra (approximately within the same horizontal plane), dorsal to the oculomotor foramen, and ventral to the trochlear foramen. The presence of a single trigeminal fenestra indicates that the ophthalmic and maxillomandibular branches of the trigeminal nerve split external to the endocranial cavity. The oculomotor foramen is the smallest of the three foramina and is positioned dorsal to the external foramen of the abducens (VI) nerve. The trochlear foramen is relatively large and is the dorsalmost foramen on the lateral surface of the braincase.

\section{Endocranial CASt}

\section{Figures 6-8}

General: The cranial endocast of BYU 17096 is complete in that it terminates anteriorly at the opening for the olfactory tracts and posteriorly at the foramen magnum (fig. 6). A small amount of bilateral asymmetry is present in the shape of the endocranial cast reflecting postmortem distortion of the braincase. The volume of the endocranial cast in BYU 17096 is $125.14 \mathrm{~cm}^{3}$. This value may be slightly inflated due to a large fracture on the right side of the braincase. The endocast is $72.5 \mathrm{~mm}$ in total anteroposterior length and $49.4 \mathrm{~mm}$ in dorsoventral depth, making it relatively short and deep (as in most sauropods; Hopson, 1979; table 1). Cerebral and pontine flexures are prominent, giving the endocast a sigmoid shape (in lateral view; fig. 7) that differs from the tubular casts of some theropods and ornithischians (e.g., Marsh, 1877; Hopson, 1979; Brochu, 2000; Larsson et al., 2000; Franzosa, 2004; Sampson and Witmer, 2007).

In ventral and dorsal views, the outline of the endocranial cast exhibits regions of lateral expansion and medial constriction rather than a more uniform tubular shape (figs. 7, 8). The greatest mediolateral breadth of the endocranial space lies across the cerebral hemispheres of the forebrain, whereas the narrowest point lies in the hindbrain just posterior to the cerebellum. Tidwell and Carpenter (2003) described the "midbrain" as the widest portion of the brain in sauropods. Presumably they were referring to the anteroposterior middle of the endocast rather than the midbrain proper (i.e., metencephalon), as they also note that the sauropod endocast is narrowest across the optic lobes (which probably would be the widest portion of the mesencephalon, but the optic lobes are not defined in sauropod endocasts: see below; Hopson, 1979). The frontals, whose ventral surfaces reflect the morphology of the anterior portion of the cerebral hemispheres, are absent in the titanosauriform described by Tidwell and Carpenter (2003), which may account for the disparate observations.

ForEBRAIN: The visible features of the forebrain and its associated anatomy include the olfactory tracts, cerebral hemispheres, optic (II) nerves, and pituitary body. A short length of the paired olfactory tract is visible anteriorly as a single midline structure extending posteroventrally from the large medial opening between the orbitosphenoids and frontals to the point where they communicate with the main body of the telencephalon. The 

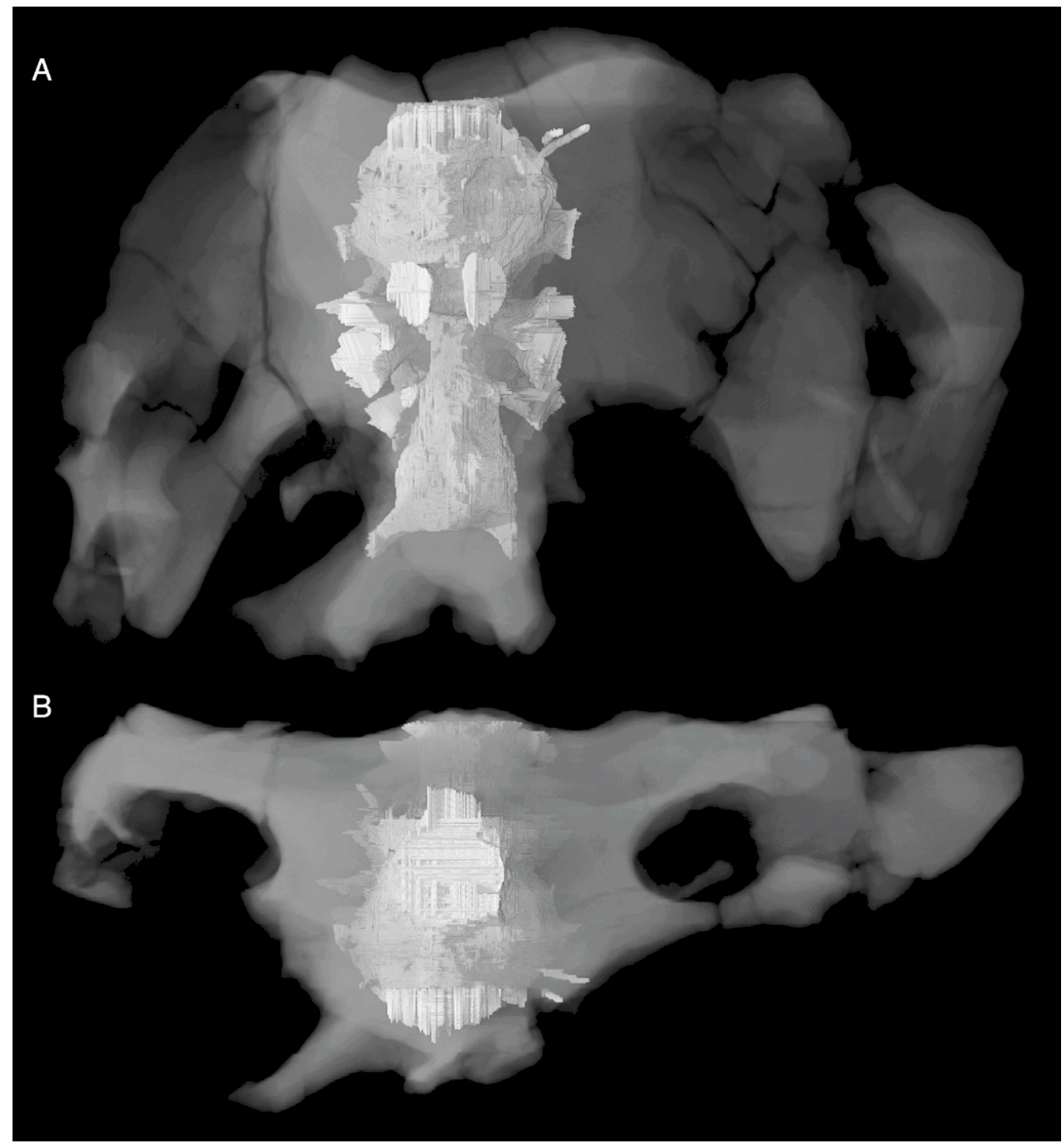

Fig. 6. Three-dimensional digital reconstruction of BYU 17096 in anterior (A) and dorsal (B) views. The endocranial space is rendered opaque (white) and the surrounding bone is rendered transparent.

path of these tracts is reflected on the medial surface of the orbitosphenoids. The combined width of the olfactory tracts is nearly equal to that of the cerebral hemispheres. The olfactory (I) nerves and bulbs are not preserved on the endocast as they are anterior to the braincase. The cerebral hemispheres are anteroposteriorly shortened and somewhat expanded lateral- ly. Their posterior margin is delineated by an indentation that runs dorsoventrally and separates the cerebral hemispheres from the inferred position of the optic tectum.

A small, paired canal is present in the space around the main body of the telencephalon near the base of the olfactory tracts (figs. 7, 8). These canals extend lateral and slightly 

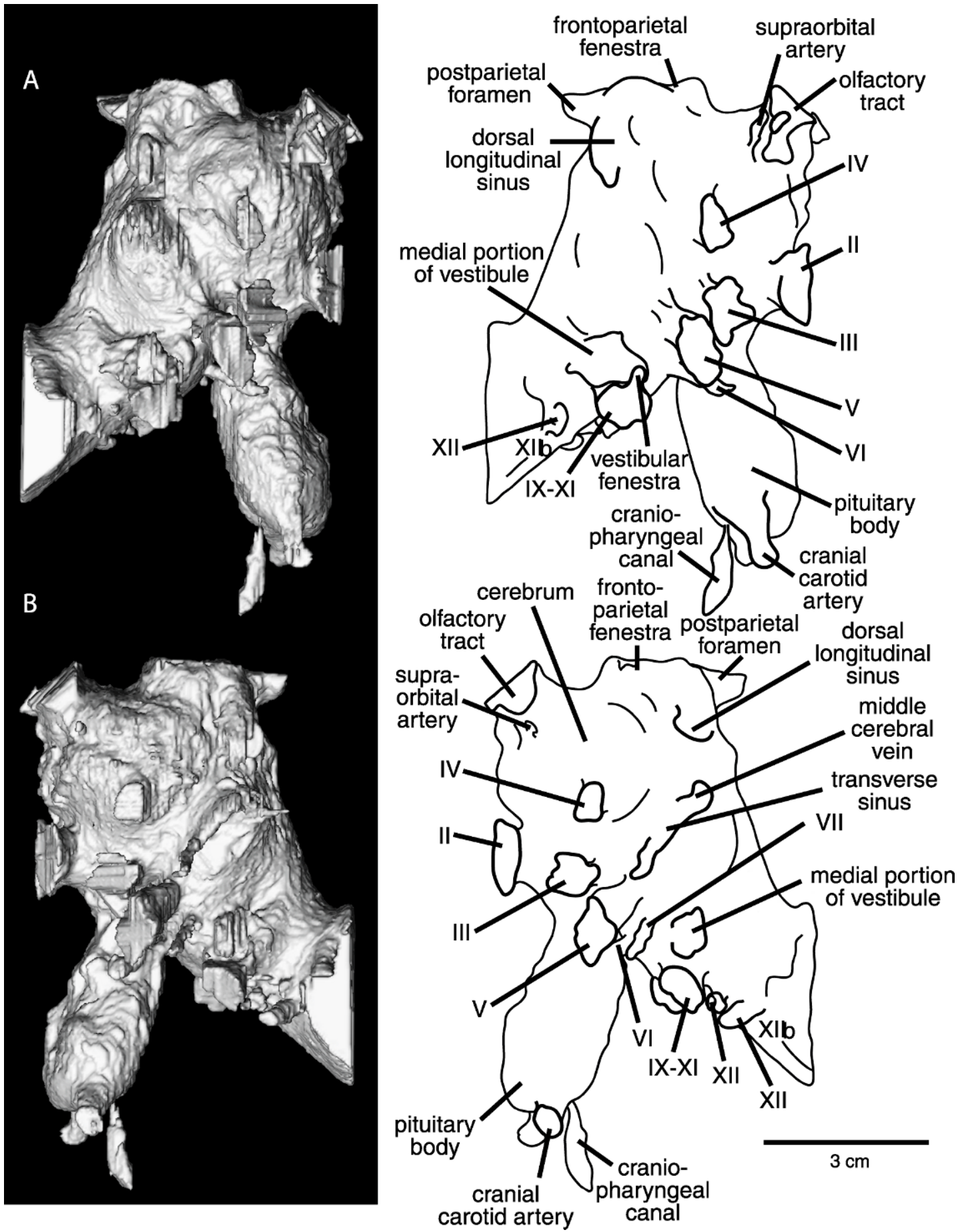

Fig. 7. Three-dimensional isosurface rendering and line drawings of the endocranial cast of BYU 17096 in right lateral (A) and left lateral (B) views. The second branch of the hypoglossal (XII) nerve, which could not be isolated digitally (see text), is marked by $\mathrm{XII}_{\mathrm{b}}$. 

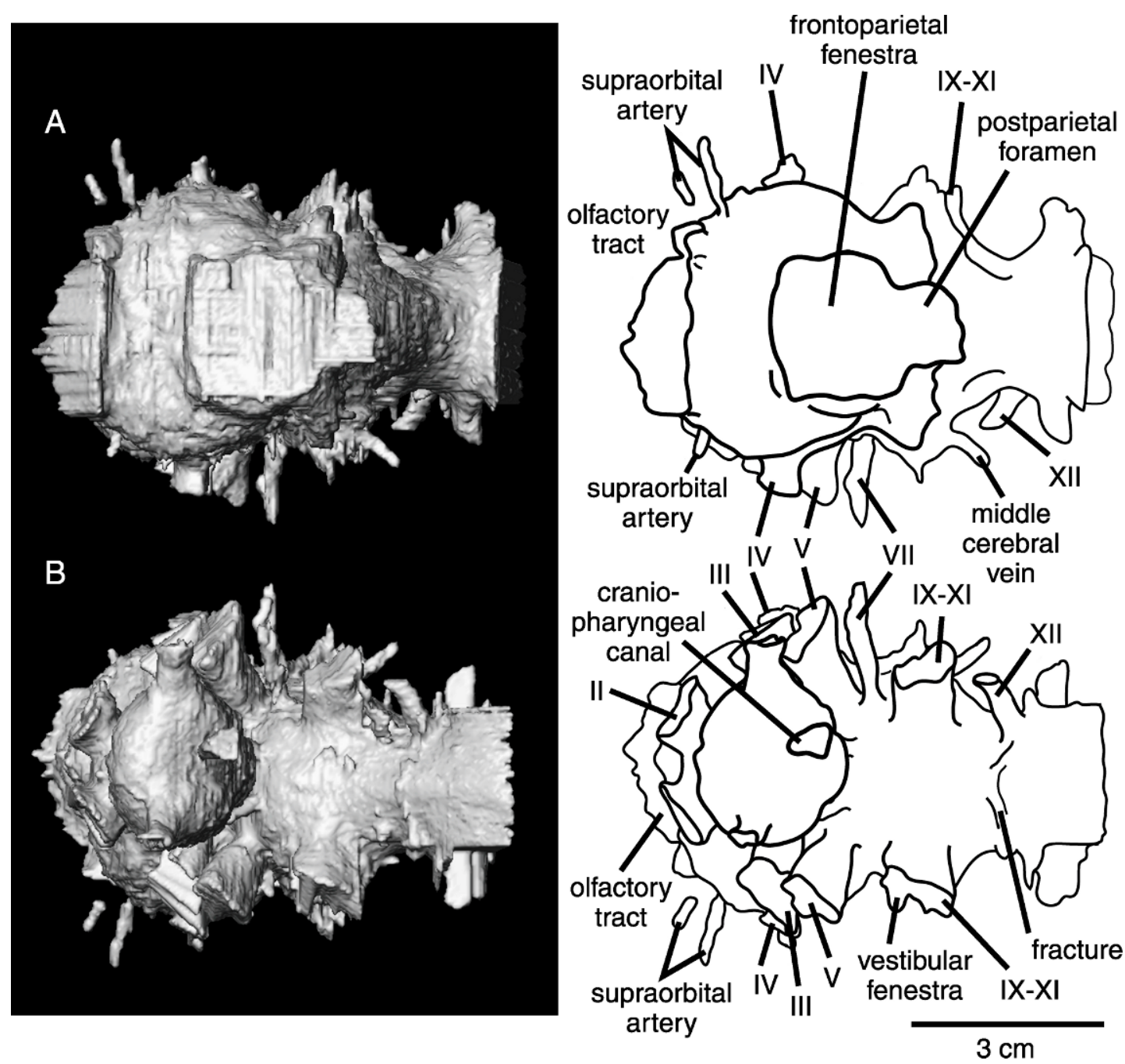

Fig. 8. Three-dimensional isosurface rendering and line drawings of the endocranial cast of BYU 17096 in dorsal (A) and ventral (B) views.

anterior through the frontal to exit the skull in the dorsomedial wall of the orbit. These structures are not described in previous studies of sauropod endocasts, but they may reflect the path of the supraorbital artery (a branch of the ophthalmic artery; Baumel and Witmer, 1993) along the lateral wall of the endocranial space through the frontal to the supraorbital foramen and into the orbit. The optic (II) nerves enter the endocranial cavity through a pair of large, circular foramina in the laterosphenoid (with a small contribution from the orbitosphenoid). These nerves extend posteromedially to converge at the midline of the anteroventral margin of the main body of the diencephalon. Also part of the diencephalon, the pituitary body descends from the ventral surface of the endocast and exhibits extreme hyperdevelopment. The infundibular stalk is directed slightly posteroventrally, whereas the pituitary body overall is oriented anteroventrally (fig. 7).

The sella turcica, which houses the pituitary body (combined hypophysis and infundibulum), is pierced by at least six distinct canals. Two of these canals represent the paired cranial carotid canals that pass through the parabasisphenoid to enter the lateral margins 


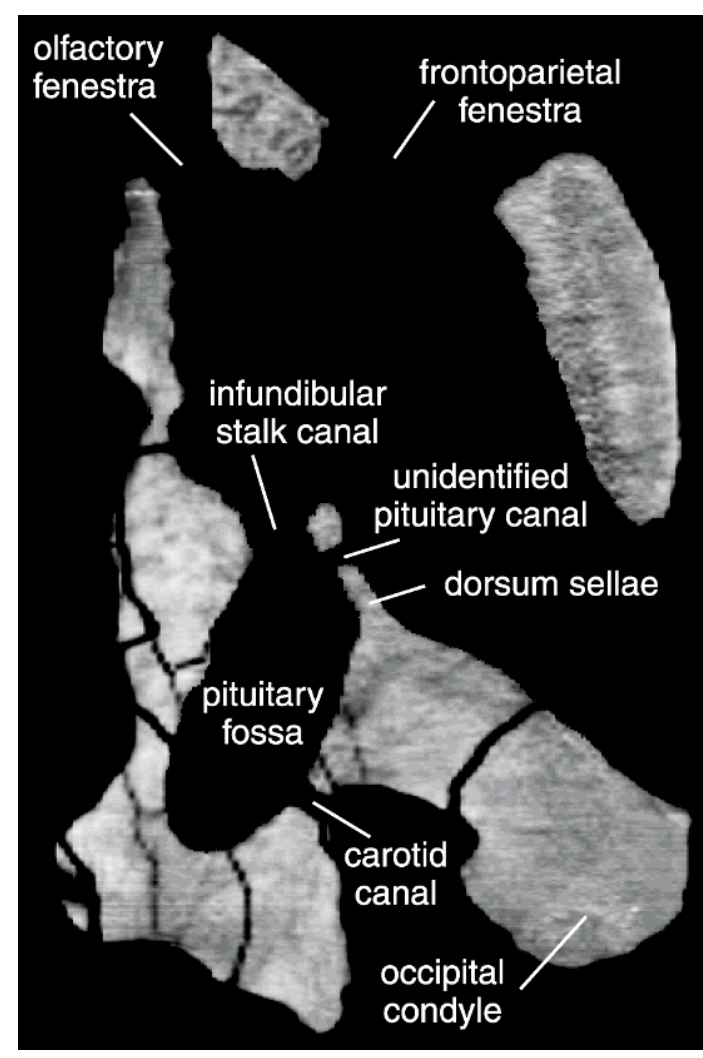

Fig. 9. Two-dimensional HRCT slice through a sagittal plane of the braincase of BYU 17096 showing two of the six canals opening into the sella turcica.

of the sella turcica near the distal end of the pituitary body (fig. 8). The third canal is a midline structure that opens onto the ventral surface of the parabasisphenoid and extends dorsally to enter the sella turcica at the distal end of the pituitary body. The canal narrows as it approaches the sella turcica. This structure is the craniopharyngeal canal (fig. 1D; Edinger, 1942), which is an adult remnant of the embryonic hypophyseal fenestra-the space separating the posterior ends of the cartilaginous trabeculae in the developing skull (Edinger, 1942; Bellairs and Kamal, 1981). The craniopharyngeal canal is variably present in sauropods and a variety of other vertebrates (Edinger, 1942); however, the phylogenetic distribution of this canal as an adult structure has never been comprehensively surveyed. The craniopharyngeal canal is known to be polymorphic in the only extant species where it has been studied explicitly (i.e., humans; Hauser and De Stefano, 1989). In humans, the canal normally is closed during prenatal development and its retention in adults often is linked to pathology and large adult body size (Chen, 2001). Tidwell and Carpenter (2003) described this opening in a titanosauriform braincase as the hypophyseal fenestra and suggested that it housed the pituitary vein. The pituitary vein is a transverse structure connecting the venous sinuses of the left and right orbit (Goodrich, 1930; Romer, 1956), and therefore is not likely to have traversed the craniopharyngeal canal to exit onto the ventral surface of the braincase in sauropods. There is no evidence in BYU 17096 of an interorbital canal (by which the pituitary vein passes through the parabasphenoid between the orbits).

The other three canals that enter the sella turcica all penetrate the dorsum sellae. Two of these canals represent the paths of the bilaterally symmetrical abducens (VI) nerves (figs. 5, 7), which penetrate the dorsum sellae along its lateral margins (see hindbrain below). A third canal extends through the dorsum sellae along the sagittal midline at a position dorsal to the abducens canal (approximately two-thirds the height of the dorsum sellae; fig. 9). The diameter of this canal is slightly larger than those of the abducens canals. It is unclear what structure, if any, was transmitted through this opening, but it appears to represent a true anatomical feature. A similar midline penetration of the dorsum sellae that is distinct from the abducens canal is present in Plateosaurus (personal observation of AMNH 6810). This shared opening may represent a derived ontogenetic trajectory in which the posterior wall of the sella turcica does not fully ossify, however, the lateral surface of this opening in Plateosaurus is finished in a way that suggests it housed a soft-bodied structure.

The shape of the dorsum sellae, as reflected by the space immediately posterior to the pituitary body in the endocast, is relatively tall and compressed along its long axis with a distal (anterodorsal) margin that tapers to a finely rounded edge. We assessed the compression of the dorsum sellae by measuring the angle formed between the posterior margin of 

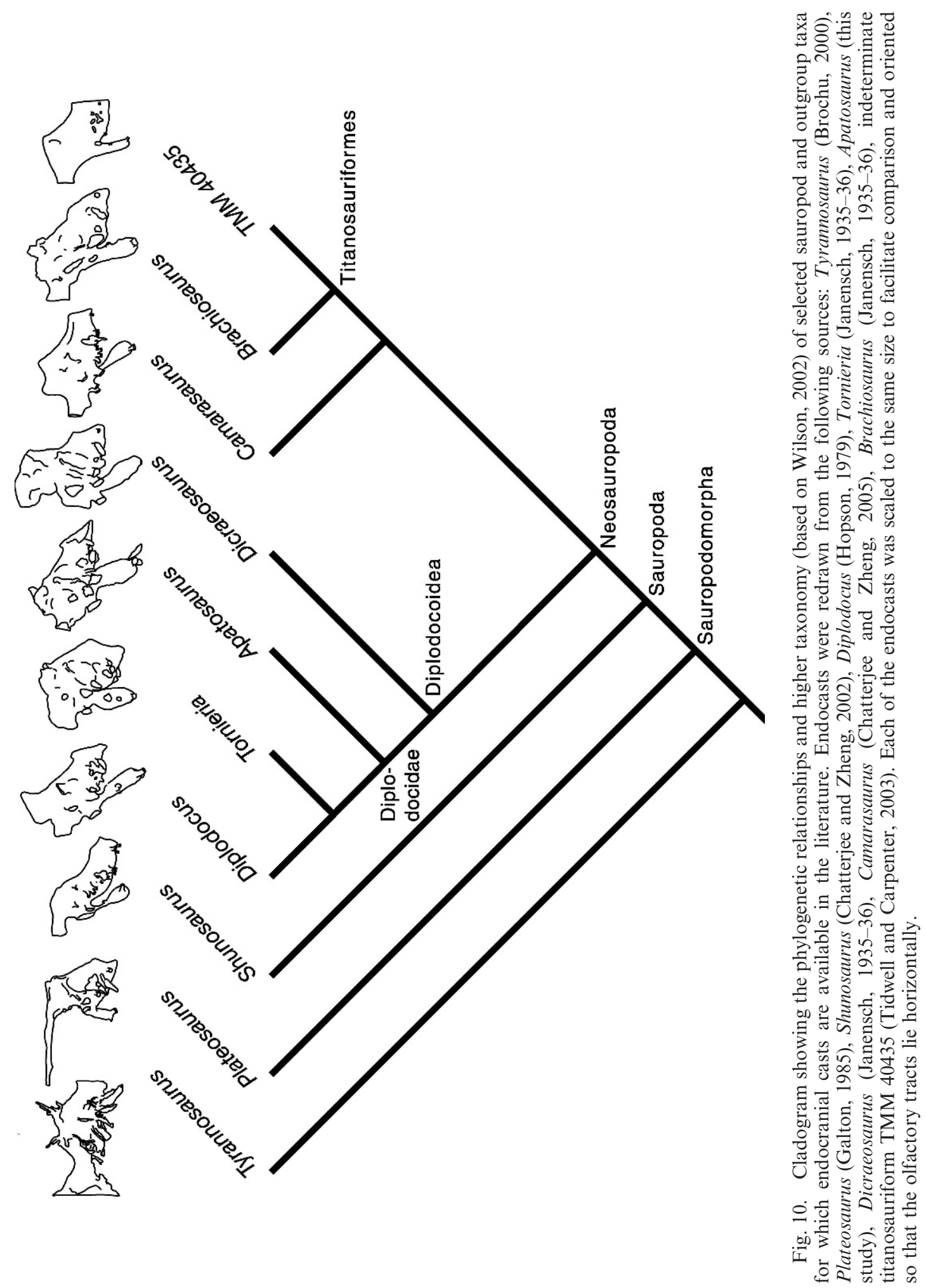
the pituitary at the base of the infundibular stalk and the foramen of the abducens canal on the posterior margin of the dorsum sellae (i.e., on the ventral margin of the endocast). This angle in BYU 17096 is $18^{\circ}$.

A large dorsal convexity, lying on top of the cerebral hemispheres along the sagittal midline, is interpreted to reflect an expanded dural venous sinus (superior sagittal or combined dorsal longitudinal-transverse sinus) and parietal body (Hopson, 1979; Witmer and Ridgely, 2009). This sinus largely fills the space formed by the frontoparietal fenestra in the dermal skull roof (between the frontals and parietals, see above) and therefore does not have a well-defined shape over most of its surface area. The superior sagittal sinus does exhibit at its posterolateral margins a bilaterally symmetrical pair of rounded ridges that reflect its enclosure within the paired parietals (fig. 7).

Midbrain: Visible structures of the midbrain include the oculomotor (III) and trochlear (IV) nerves. The inferior and superior colliculi, as well as the optic lobes, are not clearly discernible. The oculomotor (III) nerve is positioned on the ventrolateral surface of the mesencephalon directly posterior to the optic nerve and directly anterior to the larger trigeminal nerve. The oculomotor canal is large, comparable in size to that of the optic nerve, and not fully divided from the external opening of the trigeminal fenestra laterally. The position of the trochlear nerve is anteroposteriorly intermediate to the optic and oculomotor nerves (anterior and posterior, respectively) and dorsal to both.

The rostral middle cerebral vein is visible as a ridge running dorsoventrally along the lateral surface of the endocast just anterior to the midbrain (fig. 7B). The path of this vein does not extend along a straight dorsoventral trajectory but rather follows the anterior margin of the midbrain whose shape is slightly convex anteriorly (in lateral view). The rostral middle cerebral vein fully contacts the surface of the midbrain only at the apex of this anterior convexity. This vein is most easily seen on the right side of the specimen. This asymmetry probably reflects differential preservation rather than a true anatomical asymmetry, although the latter is a possibility.
HindBRAIN: The features in the region of the hindbrain that are visible on the endocranial cast include the cerebellum, trigeminal (V), abducens (VI), and facial (VII) nerves (metencephalon), as well as the medulla oblongata, glossopharyngeal (IX), vagus (X), accessory (XI), and hypoglossal (XII) nerves (myencephalon). Although its general shape is visible, details of the cerebellum are difficult to discern, probably because of the presence of an occipital sinus that likely covered this region of the brain (Hopson, 1979; Sedlmayr, 2002). The flocculus is not clearly present, although this region of the braincase is difficult to interpret due to poor differentiation in the HRCT data.

The paired trigeminal (V) nerve passes between the laterosphenoid and prootic from a position on the rhombencephalon dorsal to the pituitary body (in lateral view) and directly posterior to and in the same horizontal plane as the oculomotor (III) nerve. As noted above, the presence of a single trigeminal fenestra indicates that the gasserian ganglion lies extracranially (Hopson, 1979). A slender abducens (VI) nerve is visible on the ventrolateral surface of the endocast, passing medial and slightly ventral to the trigeminal. The abducens nerve enters the pituitary fossa after passing through the dorsum sellae along a straight, posterodorsal trajectory. There is no evidence that the abducens nerve passes lateral to the sella turcica in any sauropod, as it does (as a derived condition) in some theropod dinosaurs (Franzosa, 2004; Witmer and Ridgely, 2009). The facial (VII) nerve is reflected on the endocast as a structure relatively small in diameter and positioned posterior to the trigeminal nerve and anterodorsal to the metotic fenestra. This nerve can be traced only on the right side of the endocast.

The posterior region of the endocranial cast contains a relatively large structure that is the endocast of the cavum metoticum. This space transmitted the jugular vein and cranial nerves IX-XI out of the skull and housed the extracapsular length of the perilymphatic duct. The anterior portion of this structure includes the space homologous to the fenestra vestibuli; their division is obscured, probably reflecting a delayed ossification of at least the lateral margin of the crista interfenestralis. 
This delayed ossification also results in a broad path for the perilymphatic duct between the otic capsule and cavum metoticum. The general position and extent of the vestibular cavity of the inner ear is visible in the HRCT images, although we were not able to discern details of the semicircular canals.

The medullary portion of the hindbrain is relatively short anteroposteriorly (fig. 8B). Its mediolateral width is constricted relative to the more anterior portions of the brain, but its cross-sectional shape is slightly compressed dorsoventrally. Two hypoglossal (XII) nerves extend laterally and exit through the basioccipital at a position posterior and slightly ventral to the accessory canal. The second, more posterior canal was traced with difficulty in the HRCT slices because of the large number of fractures that are present in this region (on both sides of the skull). The second hypoglossal nerve therefore is not represented on the endocranial cast (but its position is marked as " $\mathrm{XII}_{\mathrm{b}}$ "; fig. 7); however, the second hypoglossal foramen is easily distinguished on the external, ventral surface of the basioccipital. A third hypoglossal canal is present on the left side of the endocast and is unique in its close distal proximity to the cavum metoticum (see above).

\section{Phylogenetic Diagnosis of BYU 17096}

A total of 23 characters from the phylogenetic analysis of Wilson (2002) for Sauropoda are observable on the braincase and associated dermal roofing elements of BYU 17096. Eleven of these characters exhibit the derived state for Sauropoda or more exclusive clades nested within Sauropoda, thereby allowing BYU 17096 to be diagnosed based on published apomorphic features. A frontal-frontal contact that is sutured but not fully fused, a temporal bar whose anteroposterior length is less than its transverse width, lateral exposure of the supratemporal fossa reflecting a ventral shift in the position of the temporal bar, and an occipital region that is flattened (rather than convex) with paroccipital processes that are oriented transversely (rather than posterolaterally) are synapomorphies that support BYU 17096 as nested within Sauropoda (or Eusauropoda based on a DELTRAN [delayed transformation] optimization because Vulcanodon lacks a skull; Raath, 1972; Wilson, 2002). The absence of a contribution from the frontal to the supratemporal fossa, the presence of a ventral process of the postorbital that is broader transversely than anteroposteriorly, an occipital process of the parietal that is twice the diameter of the foramen magnum, and a supratemporal fenestra that is broader transversely than anteroposteriorly diagnoses BYU 17096 to a more inclusive clade within Eusauropoda that based on ACCTRAN (accelerated transformation) optimization excludes only Shunosaurus (DELTRAN optimization of the shape of the ventral process of the postorbital is diagnostic of the slightly more exclusive Neosauropoda + Jobaria clade; Wilson, 2002: tables 9, 10). A single character - distance separating the supratemporal fenestrae twice the length of the supratemporal fenestrae along their long axis - places BYU 17096 within Neosauropoda.

Two synapomorphies diagnose BYU 17096 to Diplodocoidea: the presence of a parietal contribution to the posttemporal fenestra and orientation of the basal tubera at approximately a $45^{\circ}$ angle to the skull roof (rather than perpendicular to it). The presence of a ventrally directed occipital condyle was considered to be diagnostic of Flagellicaudata - a slightly more exclusive clade within Diplodocoidea (Harris and Dodson, 2004; see also Wilson, 2002; Harris, 2006; Remes, 2006). A third character, basipterygoid processes at least four times longer than the diameter of their base, also appears to support this specimen as a diplodocoid, but because the basipterygoid processes are partially broken, we refrain from scoring this character for BYU 17096.

The eleventh synapomorphy is the presence of a distinct recess positioned between the paired basipterygoid processes. The presence of this recess is plesiomorphic for Sauropoda with a transformation of this recess into a rounded shelf diagnosing Neosauropoda. A reversed condition within Neosauropoda, in which the recess is present, is found in the titanosaurid Nemegtosaurus (Wilson, 2002, 2005) and in the diplodocid Apatosaurus. Because BYU 17096 can be diagnosed to Diplodocoidea based on at least two synapomorphies, the presence of the basipterygoid recess unambiguously allocates this specimen to Apatosaurus. Additional support for a 
diagnosis to Apatosaurus may be drawn from the angle separating the basipterygoid processes. We approximated this angle in BYU 17096 to be roughly $60^{\circ}-70^{\circ}$. Upchurch et al. (2004) concluded that a $60^{\circ}$ angle, rather than the $40^{\circ}$ $45^{\circ}$ angle found in most sauropods, is diagnostic of Apatosaurus. An angle of approximately $45^{\circ}$ was considered the plesiomorphic condition for Sauropoda by Wilson (2002), with a smaller angle of less than $30^{\circ}$ a derived condition that diagnoses Dicraeosauridae and is convergently present in the titanosaur Rapetosaurus (Wilson, 2002). An angle significantly larger than $45^{\circ}$ was not defined as a derived state by Wilson (2002). An angle of approximately $90^{\circ}$ was reported for Shunosaurus (Chatterjee and Zheng, 2002), suggesting that the plesiomorphic condition may not be $40^{\circ}-45^{\circ}$. This angle seemingly needs reassessment for Sauropoda, probably as a continuous character with well-defined landmarks and taking into account the potential for significant postnatal repatterning and variation due to diagenetic distortion.

Robust basitubera, the massive nature of the occipital condyle, and basipterygoid processes that are relatively short and stout are characters shared between BYU 17096 and the wellpreserved braincases of Apatosaurus (YPM 1860 and CM 11162) that differ with known specimens of Diplodocus, and therefore represent potential autapomorphies of Apatosaurus. These characters need to be formally defined and surveyed across a broadened taxonomic spectrum and in the context of a specific phylogenetic hypothesis.

\section{DISCUSSION}

A number of features described in BYU 17096 appear to vary within Sauropoda and therefore present the possibility of establishing new phylogenetically informative characters from the sauropod braincase, and in some cases, suggest that established characters are in need of critical review. Although the comprehensive review of sauropod braincase morphology needed to meaningfully establish the evolutionary history of these characters or adequately revise them is outside the scope of this project, a number of these characters do provide points of discussion that hopefully will act as a catalyst for future research. It is important to emphasize that the purpose of the following discussion is to establish baseline hypotheses of evolutionary transformations in the sauropod braincase based on current understanding of the morphology and taxonomic distribution of these features as established from the published literature, and to point out areas of apparent variation that may be phylogenetically informative but in need of further research. The discussion is not meant as an endorsement of the literature from which it is derived or as a critical review of published observations - but rather as a starting point for such a review.

\section{Cerebral and Pontine Flexures}

The sigmoid shape of the endocast in BYU 17096 is due to the development of both the cerebral and pontine flexures such that they form nearly $90^{\circ}$ angles with the horizontal and vertical planes respectively (fig. 7). As noted above, this shape differs markedly from the tube-shaped, linear endocranial casts of basally diverging theropods (e.g., Brochu, 2000; Sampson and Witmer, 2004) and ornithischians (e.g., Stegosaurus; Marsh, 1877; Galton, 2001; Galton and Upchurch, 2004), indicating that the evolution of these flexures is independently derived along the prosauropod-sauropod branch of the saurischian tree. The endocranial casts of Plateosaurus, Shunosaurus, and Camarasaurus exhibit marked cerebral and pontine flexures relative to the above outgroups (Galton, 1985; Chatterjee and Zheng, 2002, 2005; Ostrom and McIntosh, 1966). This distribution indicates that a distinctly flexed endocranial space is plesiomorphic for Sauropodomorpha (fig. 10). The flexure of this space in Plateosaurus, Shunosaurus, and Camarasaurus is not as highly developed as that found in Apatosaurus, Tornieria, Diplodocus, Dicraeosaurus, Brachiosaurus, and the TMM titanosauriform. The taxonomic distribution of this more extreme flexure indicates that either this condition evolved once as a transformation diagnostic of Neosauropoda and was subsequently reversed in Camarasaurus, or the relatively flattened endocranial space of Camarasaurus is plesiomorphic and the highly developed flexures evolved twice within Neosauropoda-once in the diplodocoid lineage and 
once in the titansauriform lineage (fig. 10). The subtle nature of these differences obviously makes distinguishing discrete character states difficult and uncomfortably subjective. These flexures therefore should be reexamined morphometrically once an expanded taxonomic sample is available.

\section{Pituitary Body and Dorsum Sellae}

The dorsum sellae (fig. 9), as reflected by the space immediately posterior to the pituitary body in the endocast (fig. 7), is a relatively elongate structure in BYU 17096 that is distinctly compressed along its long axis and exhibits a finely rounded distal margin. This anteroposteriorly compressed shape also is present in Tornieria (Janensch, 1935-36), Diplodocus (Ostrom and McIntosh, 1966; Hopson, 1979; Galton, 1985; Franzosa, 2004), Dicraeosaurus (Janensch, 1935-36), and Brachiosaurus (Janensch, 1935-36; see also Tidwell and Carpenter, 2003), and contrasts with the more broadly rounded dorsum sellae of Shunosaurus (Chatterjee and Zheng, 2002), Camarasaurus (Ostrom and McIntosh, 1966; see also fig. 2 of Tidwell and Carpenter, 2003), and the TMM titanosauriform described by Tidwell and Carpenter (2003). We attempted to quantify these differences by measuring the angle between the posterior margin of the pituitary at the base of the infundibular stalk and the foramen of the abducens canal on the posterior margin of the dorsum sellae (i.e., ventral margin of the endocast; fig. 7). This angle in BYU 17096, Tornieria, Diplodocus, Dicraeosaurus, and Brachiosaurus is approximately $18^{\circ}, 16^{\circ}, 32^{\circ}$, $38^{\circ}$, and $39^{\circ}$ respectively, whereas the angle in Plateosaurus, Shunosaurus, the titanosauriform, and Camarasaurus is $72^{\circ}, 52^{\circ}$, and $75^{\circ}$ respectively (fig. 10).

The infundibular stalk of BYU 17096 is directed slightly posteroventrally (fig. 7); however, overall the pituitary body is oriented anteroventrally, differing from the posteroventral angle of Diplodocus. The pituitary also is larger and more bulbous than in Diplodocus (Franzosa, 2004). This overall anteroventral orientation differs from that of all other sauropod taxa for which endocranial casts are available. In other sauropods, as well as in theropods (e.g., Tyrannosaurus, Brochu, 2000; Acrocanthasaurus, Franzosa and Rowe, 2004), the pituitary body as a whole is angled posteroventrally rather than anteroventrally. The accuracy of the perceived differences in pituitary orientation suffers from the lack of a completely reliable comparator for orienting the endocasts involved in these comparisons. The best comparator might be the lateral semicircular canal (e.g., Alonso et al., 2004), but this structure is not reconstructed for many of the taxa in this comparison including BYU 17096. We used the general orientation of the olfactory tracts as our reference, which is problematic (see Sereno et al, 2007). The point we stress here is that variation in the orientation of the pituitary body does appear to occur within Sauropoda and therefore is potentially informative - phylogenetically or otherwise.

Whereas in Diplodocus a craniopharyngeal canal extends from the base of the pituitary fossa through the ventral surface of the basisphenoid (Edinger, 1942; Franzosa, 2004), the craniopharyngeal canal in BYU 17096 extends ventrally to open between the basal tubera. This feature likely is variable intraspecifically (Edinger, 1942).

\section{Frontoparietal Fenestra}

Figures 2, 8

The terms parietal and postparietal foramen are historically used to describe the openings in the dermal roof of the braincase that form communications with the underlying endocranial space. The term "parietal foramen" generally is assigned when a single dorsal opening is present (e.g., Chatterjee and Zheng, 2002). As noted above, this terminology implies a primary homology between this opening in sauropods and the parietal foramen of other reptile taxa, such as some lepidosaurs, in which the foramen houses the photoreceptive parietal (pineal) organ (Quay, 1979; the parietal opening generally is lost in archosaurs; Roth and Roth, 1980). "Parietal foramen" is applied whether this opening closely resembles that of other reptile groups in which it is relatively small, as in Shunosaurus (Chatterjee and Zheng, 2002), or it is distinctively large, as in BYU 17096 (although see Hopson, 1979). The presence of a second, posteriorly positioned "postparietal" foramen is 
a derived character within Sauropoda that unambiguously diagnoses Dicraeosauridae (Amargasaurus + Dicraeosaurus; Wilson, 2002). A postparietal foramen also is present in Suuwassea (Harris, 2006), which currently is placed in an unresolved trichotomy with Diplodocidae and Dicraeosauridae (Harris and Dodson, 2004). This means that the postparietal foramen may be apomorphic for this more inclusive clade and therefore lost in Diplodocidae. The postparietal foramen in Amargasaurus is fully distinct from the parietal foramen because of a broad medial contact between the paired parietals between these openings. In Dicraeosaurus, the parietal and postparietal foramina retain a small degree of confluence because the parietals closely approach each other along the sagittal midline but fail to actually contact.

The phylogenetic distribution of the extremely large "parietal foramen," which is such a unique feature in the sauropod specimens that contain it, has never been explicitly surveyed (the most detailed discussion of these features remains that of Janensch, 1935-36); however, it does appear to be relatively common and taxonomically widespread within Sauropoda. In specimens that contain this large opening, the medial margins of the parietals forming the posterolateral margin of the "foramen" often turn slightly inward, resulting in a subtle but partial division of this expanded opening into a large anterior portion and a much smaller posterior opening (this is true of BYU 17096, see above). This division is not as clearly developed as that exhibited by Dicraeosaurus, and whereas the resultant anterior foramen in these specimens remains distinctively large, the posterior foramen is approximately the same relative size as the postparietal foramen of Dicraeasaurus and Amargasaurus. These observations suggest that, although the degree to which the "postparietal" foramen is closed off anteriorly by the parietals is unique in Dicraeosauridae, a space homologous to the postparietal foramen of dicraeosaurids may be more broadly distributed in Sauropoda than reflected in the character matrix of Wilson (2002).

The presence of a postparietal foramen, whether fully or nearly closed as in dicraeosaurids, or broadly confluent anteriorly as in BYU
17096, suggests that at least two soft structures pass through the dermal skull roof from the endocranial space (or at least filled these foramina in life). The anterior margin of the supraoccipital, which forms the posterior margin of the "postparietal" foramen, is concave forming a distinct vertical groove in BYU 17096 (see above). A similar groove is present in the caudal margin of the postparietal foramen of the dicraeosaurids (see Remes, 2006) and presumably reflects the shape of the structure housed within this space. The relative size of the postparietal foramen, even in specimens where it is broadly confluent anteriorly (e.g., BYU 17096), closely compares in size with the parietal foramen of Shunosaurus and most other reptiles (e.g., squamates). The anterior opening likely housed in part the pineal body, whereas the postparietal foramen is likely associated with a dural venous sinus (Witmer and Ridgely, 2009). The nature and polarity of the morphological transformations involved in the evolutionary history of these structures within sauropods cannot be interpreted meaningfully until a more comprehensive survey of their presence/absence is available.

\section{Cranial Nerves}

\section{Figure 5}

The optic (II) nerve of BYU 17096 passes laterally out of the endocranial space into the orbital fossa at the anterior margin of the laterosphenoid (with a small contribution to this canal from the orbitosphenoid). This morphology is the most common condition in sauropods (and archosaurs in general; Goodrich, 1930; Baumel and Witmer, 1993) and therefore likely represents the plesiomorphic condition within Sauropoda. The optic nerves of Shunosaurus are described as exiting between the orbitosphenoid and laterosphenoid (Zheng, 1991; Chatterjee and Zheng, 2002), but are figured as exiting the endocranial space anteriorly through a single medial opening between the paired orbitosphenoids directly below the midline opening for the olfactory tracts (see fig. 7, Chatterjee and Zheng, 2002). A third morphology in which the optic fenestra opens laterally but the canal and associated foramen lie completely within the orbitosphenoid was described for Apato- 
saurus (see fig. 11D of Berman and McIntosh, 1978). The latter two conditions are interpreted as derived within sauropods.

The trigeminal nerve passes through the laterosphenoid-prootic margin within a single fenestra in Apatosaurus (this study; Berman and McIntosh, 1978), Diplodocus (Holland, 1906; Berman and McIntosh, 1978; Franzosa, 2004; Sereno et al., 2007), Brachiosaurus (Janensch, 1935-36; Tidwell and Carpenter, 2003), Camarasaurus (Sereno et al., 2007), Plateosaurus (Galton, 1985), and most other sauropods (e.g., titanosauriform of Tidwell and Carpenter, 2003) indicating that within these taxa the gasserian ganglion is positioned extracranially. Hopson (1979) described an extracranial position of this ganglion as the condition in all sauropods. An intracranial position for this ganglion is described in Shunosaurus and Camarasaurus based on the presence of multiple canals and foramina inferred to transmit the ophthalmic, maxillary, and mandibular branches of the trigeminal nerve (Chatterjee and Zheng, 2002, 2005). Sereno et al. (2007), however, found an extracranial split of the trigeminal nerve (i.e., only one trigeminal fenestra in the skull). If the interpretations of Chatterjee and Zheng are correct for Camarasaurus, then there is at least one reversal of this morphology in Sauropoda (along the Camarasaurus lineage).

The glossopharyngeal (IX), vagus (X), and accessory (XI) nerves and the jugular vein are interpreted to pass through an undivided cavum metoticum and exit the braincase through the metotic fenestra. An undivided cavum metoticum (inferred from a single described external opening) also is present in Plateosaurus (Galton, 1985), Brachiosaurus (Tidwell and Carpenter, 2003), and Diplodocus (Berman and McIntosh, 1978) - a taxonomic distribution that suggests an undivided metotic fissure is the plesiomorphic condition for Sauropoda. Franzosa (2004) describes a fenestra pseudorotundum in HMS 175. This term refers to the lateral aperture of the recessus scalae tympani and implies a divided cavum metoticum (De Beer, 1937). This probably reflects the widespread confusion regarding the anatomical nomenclature applied to this area of the basicranium, rather than an interpretation of a divided cavum metoticum. (Franzosa [2004] explicitly interprets cranial nerves IX-XI as exiting through that opening.)

The undivided metotic fissure of sauropodomorphs represents a plesiomorphic retention of the basal archosaurian condition (Gower and Weber, 1998; Gower, 2002) that is transformed at some point in early theropod evolution (Sampson and Witmer, 2007). A separate path of the accessory nerve-which would represent at least a division of the lateral metotic fenestra if not the entire cavum metoticum-is reported for Shunosaurus (Chatterjee and Zheng, 2002), Camarasaurus (Chatterjee and Zheng, 2005), the titanosauriform of Tidwell and Carpenter (2003), and potentially the titanosauriform braincase described by Berman and Jain (1982). The identity of this foramen as transmitting the accessory nerve in these taxa might be questionable, especially considering the possibility of a variable third branch of the hypoglossal nerve (see above). A separate path of the accessory nerve, if one does exist, would be a derived variation in the basicranium of Sauropoda and therefore deserves further attention and scrutiny. Many descriptions of sauropod braincases fail to account for the accessory nerve (e.g., Hopson, 1979; Tidwell and Carpenter, 2003 for Brachiosaurus), which is not surprising as it is part of the larger vagal complex, but one could infer that this reflects the absence of a separate accessory foramen. A comprehensive and explicit survey for this foramen is needed.

A single hypoglossal foramen that exits completely within the basioccipital may be the most common condition in Sauropoda (Wilson et al., 2005). A single foramen was described on the endocast of Diplodocus (Franzosa, 2004), whereas two foramina are described for BYU 17096 (with an asymmetric third foramen on the left side; fig. 5) and the Diplodocus specimen described by Berman and McIntosh (1978). Chatterjee and Zheng (2002) described the hypoglossal in Camarasaurus as splitting into two major branches as it emerges from the braincase. Tidwell and Carpenter (2003) note that in Camarasaurus and Brachiosaurus the hypoglossal foramina are absent, and suggest that the hypoglossal nerve(s) in those specimens may have exited the skull through the metotic fenestra. Such a 
configuration would require a considerable reorganization of the neuro- and basicranial anatomy, as it presumably would require that the hypoglossal nerves branch from the myencephalon at a much more anterior position so that they are "captured" by the cavum metoticum - a configuration not known to occur in any described extant amniote of which we are aware. Support for the lateral capture of a hypoglossal nerve by the metotic fenestra, however, might be drawn from the close proximity of the metotic fenestra with lateral opening of the asymmetric third hypoglossal canal in BYU 17096. The number of distinct foramina transmitting branches of the hypoglossal nerve certainly exhibits variation within Sauropoda and therefore is potentially informative. The potential for ontogenetic and individual variation in the number and position of these foramina, however, may require relatively large sample sizes to establish the presence of a phylogenetically informative signal-samples that may not be attainable for sauropods.

\section{Flocculus (Cerebellar Auricular Fossa)}

Figure 7

Chatterjee and Zheng (2002) note that the flocculus is not discernible in Shunosaurus and that this absence is probably due to a reduced need for balance and orientation control in sauropods relative to the condition in bipedal theropods. A distinct flocculus was not found in BYU 17096 or Diplodocus (Franzosa, 2004) although the reality of these absences cannot be considered definitive. If the flocculus indeed is absent in these taxa, then the loss of this structure, as well as any functional correlates, is a derived condition within Sauropodomorpha and needs to be surveyed comprehensively.

\section{CONCLUSIONS}

The endocranial morphology of sauropod dinosaurs historically was considered to exhibit little variation (Hopson 1979). Close observation of external and internal braincase features in an expanded taxonomic sample reveals the presence of considerable variation that undoubtedly is informative at a range of phylogenetic and taxonomic levels. Many of the observed differences are related to changes in proportion and shape whose meaningful delineation may require comparative morphometrics. Discrete variation in sauropod neurocranial anatomy, however, certainly is present. Recognizing the presence of variation and thus the potential for new characters is the necessary first step in acquiring a better understanding of this complex anatomical partition. Hopefully this recognition will serve as a catalyst for acquiring more data, not only from additional sauropod taxa, but also from additional specimens of taxa for which endocasts already exist. The expansion of samples that allow documenting both inter- and intraspecific variation is the only way that meaningful conclusions can be drawn regarding the evolution of the braincase and neuroanatomy in this derived group of vertebrates.

\section{ACKNOWLEDGMENTS}

We thank Kenneth Stadtman (Museum of Western Colorado, formerly of Brigham Young University Earth Science Museum) for permission to scan and study the specimen. Matt Colbert and Jessie Maisano (University of Texas at Austin) respectively HRCT scanned the specimen and helped us with posting the associated digital data for which we are grateful. We gratefully acknowledge Brooks Britt (Brigham Young University) for his photographs of the specimen. The thoughtful comments of Peter Galton, Mark Norell, and Larry Witmer significantly improved the manuscript and are greatly appreciated. John Whitlock provided valuable discussion on general braincase morphology of diplodocids. Financial assistance for this project was provided by a grant from the Jurassic Foundation (to TI and GSB), the Geology Foundation at the University of Texas at Austin, and the Division of Paleontology, American Museum of Natural History.

\section{REFERENCES}

Alonso, P.D., A.C. Milner, R.A. Ketcham, M.J. Cookson, and T.B. Rowe. 2004. The avian nature of the brain and inner ear of Archaeopteryx. Nature 430: 666-669.

Baumel, J.J., and L.M. Witmer. 1993. Osteologia. In J.J. Baumel, A.S. King, J.E. Breazile, H.E. 
Evans and J.C. Vanden Berge (editors), Handbook of avian anatomy: Nomina Anatomica Avium. 2nd ed. Publications of the Nuttall Ornithological Club 23: 45-132. Cambridge: Nuttall Ornithological Club.

Bellairs, A.d'A., and A.M. Kamal. 1981. The chondrocranium and the development of the skull in recent reptiles. In C. Gans and T.S. Parsons (editors), Biology of the Reptilia. Vol. 11. Morphology F: 1-263. London: Academic Press.

Benton, M.J., L. Juul, G.W. Storrs, and P.M. Galton. 2000. Anatomy and systematics of the prosauropod dinosaur Thecodontosaurus antiquus from the Upper Triassic of southwest England. Journal of Vertebrate Paleontology 20: $77-108$.

Berman, D.S., and S.L. Jain. 1982. The braincase of a small sauropod dinosaur (Reptilia: Saurischia) from the Upper Cretaceous Lameta Group, Central India, with review of Lameta group localities. Annals of Carnegie Museum 51: 405-422.

Berman, D.S., and J.S. McIntosh. 1978. Skull and relationships of the Upper Jurassic sauropod Apatosaurus (Reptilia, Saurischia). Bulletin of Carnegie Museum of Natural History 8: 1-35.

Brochu, C.A. 2000. A digitally rendered endocast for Tyrannosaurus rex. Journal of Vertebrate Paleontology 20: 1-6.

Butler, A.B., and W. Hodos. 1996. Comparative vertebrate neuroanatomy. New York: WileyLiss, $514 \mathrm{pp}$.

Calvo, J.O., and L. Salgado. 1995. Rebbachisaurus tessonei sp. nov. A new Sauropoda from Albian-Cenomanian of Argentina; new evidence on the origin of the Diplodocidae. Gaia 11: 13-33.

Carlson, W.D., T. Rowe, R.A. Ketcham, and M.W. Colbert. 2003. Geological applications of highresolution X-ray computed tomography in petrology, meteoritics and paleontology. In $\mathrm{F}$. Mees, R. Swennen, M. Van Geet and P. Jacobs (editors), Applications of X-ray computed tomography in the geosciences 215: 7-22. London: Geological Society.

Chatterjee, S., and Z. Zheng. 2002. Cranial anatomy of Shunosaurus, a basal sauropod dinosaur from the Middle Jurassic of China. Zoological Journal of the Linnean Society 136: 145-169.

Chatterjee, S., and Z. Zheng. 2005. Neuroanatomy and dentition of Camarasaurus lentus. In $\mathrm{V}$. Tidwell and K. Carpenter (editors), Thunderlizards: the sauropodomorph dinosaurs: 199-211. Bloomington: Indiana University Press.

Chen, C.J. 2001. Suprasellar and infrasellar craniopharyngioma with a persistent craniopharyn- geal canal: case report and review of the literature. Neuroradiology 43: 760-762.

Clark, J.M., J. Welman, J.A. Gauthier, and J.M. Parrish. 1993. The laterosphenoid of early archosauriforms. Journal of Vertebrate Paleontology 13: 48-57.

Connely, M.V., and R. Hawley. 1998. A proposed reconstruction of the jaw musculature and other soft cranial tissues of Apatosaurus. Journal of Vertebrate Paleontology 18(Suppl. to 3$): 35 \mathrm{~A}$.

Currie, P.J. 1997. Braincase anatomy. In P.J. Currie and K. Padian (editors), Encyclopedia of dinosaurs: 81-85. San Diego, CA: Academic Press.

Curtice, B.D., and D.R. Wilhite. 1996. A reevaluation of the Dry Mesa Dinosaur Quarry sauropod fauna with a description of juvenile sauropod elements. In A.C. Huffman, Jr., W.R. Lund and L.H. Godwin (editors), Geology and resources of the Paradox Basin. Utah Geological Association Guidebook 25: 325-338. Salt Lake City: Utah Geological Association.

De Beer, G. 1937 (1985). The development of the vertebrate skull. Chicago: University of Chicago Press, 744 pp.

Edinger, T. 1942. The pituitary body in giant animals fossil and living: a survey and a suggestion. Quarterly Review of Biology 17: 31-45.

Edinger, T. 1955. The size of the parietal foramen and organ in reptiles. Bulletin of the Museum of Comparative Zoology 114: 3-34.

Foster, J.R. 2003. Paleoecological analysis of the vertebrate fauna of the Morrison Formation (Upper Jurassic), Rocky Mountain region, U.S.A. Bulletin of New Mexico Museum of Natural History 23: 1-95.

Franzosa, J., and T. Rowe. 2005. Cranial endocast of the Cretaceous theropod dinosaur Acrocanthosaurus atokensis. Journal of Vertebrate Paleontology 25: 859-864.

Franzosa, J.W. 2004. Evolution of the brain in Theropoda (Dinosauria). Ph.D. dissertation, University of Texas at Austin, $357 \mathrm{pp}$.

Galton, P.M. 1985. Cranial anatomy of the prosauropod dinosaur Plateosaurus from the Knollenmergel (Middle Keuper, Upper Triassic) of Germany. Geologica et Palaeontologica 19: 119-159.

Galton, P.M. 2001. Endocranial casts of the plated dinosaur Stegosaurus (Upper Jurassic, western USA): a complete undistorted cast and the original specimens of Othniel Charles Marsh. In K. Carpenter (editor), The armored dinosaurs: 103-129. Bloomington: Indiana University Press.

Galton, P.M., and P. Upchurch. 2004. Stegosauria. In D.B. Weishampel, P. Dodson and H. Osmólska (editors), The Dinosauria. 2nd ed: 343-362. Berkeley: University of California Press. 
Goodrich, E.S. 1930 (1986). Studies on the structure and development of vertebrates. Chicago: University of Chicago Press, 837 pp.

Gower, D.J. 2002. Braincase evolution in suchian archosaurs (Reptilia: Diapsida): evidence from the rauisuchian Batrachotomus kupferzellensis. Zoological Journal of the Linnean Society 136: 49-76.

Gower, D.J., and E. Weber. 1998. The braincase of Euparkeria, and the evolutionary relationships of birds and crocodilians. Biological Reviews 73: $367-411$.

Harris, J.D. 2006. Cranial osteology of Suuwassea emilieae (Sauropoda: Diplodocoidea: Flagellicaudata) from the upper Jurassic Morrrison Formation of Montana, USA. Journal of Vertebrate Paleontology 26: 88-102.

Harris, J.D., and P. Dodson. 2004. A new diplodocoid sauropod dinosaur from the upper Jurassic Morrison Formation of Montana, USA. Acta Palaeontologica Polonica 49: 197-210.

Hauser, G., and G.F. De Stefano. 1989. Epigenetic variants of the human skull. Stutgart: Schweizerbart, $301 \mathrm{pp}$.

Holland, W.J. 1906. The osteology of Diplodocus Marsh. Memoirs of the Carnegie Museum 2: 225-278.

Hopson, J.A. 1979. Paleoneurology. In C. Gans, R.G. Northcutt and P. Ulinski (editors), Biology of the Reptilia 9: 39-146. London: Academic Press.

Janensch, W. 1935-36. Die Schädel der Sauropoden Brachiosaurus, Barosaurus und Dicraeosaurus aus den Tendaguru-Schichten Deutsch-Ostafrikas. Sonder-Abdruck aus Palaeontographica Beiträge zur Naturgeschichte der Vorzeit herausgegeben von F. Broili in München. Suppl. 7. Vol. 2: 147-297, 13 pls.

Larsson, H.C.E., P.C. Sereno, and J.A. Wilson. 2000. Forebrain enlargement among nonavian theropod dinosaurs. Journal of Vertebrate Paleontology 20: 615-618.

Madsen, J., J.S. McIntosh, and D.S. Berman. 1995. Skull and atlas-axis complex of the upper Jurassic sauropod Camarasaurus Cope (Reptilia: Saurischia). Bulletin Carnegie Museum of Natural History 31: 1-115.

Marsh, O.C. 1877. New order of extinct Reptilia (Stegosauria) from the Jurassic of the Rocky Mountains. American Journal of Science (3) 14: 513-514.

Marsh, O.C. 1880. Principal characters of American Jurassic dinosaurs. Part 3. American Journal of Science (3) 19: 253-259.

Marsh, O.C. 1884. Principle characters of American Jurassic dinosaurs. Part VII. On the Diplodocidae, a new family of the Sauropoda. American Journal of Science (3) 27: 161-167.
Marsh, O.C. 1896. The dinosaurs of North America. Annual Report of the U. S. Geological Survey 16: $133-244$.

Osborn, H.F., and C.C. Mook. 1921. Camarasaurus, Amphicoelias, and other sauropods of Cope. Memoirs of the American Museum of Natural History. new ser. v. 3. pt. 3: 247-287.

Ostrom, J.H., and J.S. McIntosh. 1966 (1999 reprint). Marsh's Dinosaurs: the collections from Como Bluff. New Haven, CT: Yale University Press, 388 pp.

Quay, W.B. 1979. The parietal eye-pineal complex. In C. Gans, R.G. Northcutt and P. Ulinski (editors), Biology of the Reptilia. Vol. 9. Neurology: 245-406. London: Academic Press.

Raath, M.A. 1972. Fossil vertebrate studies in Rhodesia: a new dinosaur (Reptilia: Saurischia) from near the Triassic-Jurassic boundary. Arnoldia 5: 1-37.

Rauhut, O.W.M., K. Remes, R. Fechner, G. Cladera, and P. Puerta. 2005. Discovery of a short-necked sauropod dinosaur from the Late Jurassic period of Patagonia. Nature 435: 670-672.

Remes, K. 2006. Revision of the Tendaguru sauropod dinosaur Tornieria africana (Fraas) and its relevance for sauropod paleobiogeography. Journal of Vertebrate Paleontology 26: 651-669.

Rieppel, O. 1985. The recessus scalae tympani and its bearing on the classification of reptiles. Journal of Herpetology 19: 373-384.

Romer, A.S. 1956. Osteology of the reptiles. Chicago: University of Chicago Press, 772 pp.

Roth, J.J., and E.C. Roth. 1980. The parietal-pineal complex among paleovertebrates: evidence for temperature regulation. In R.D.K. Thomas and E.C. Olsen (editors), A cold look at the warmblooded dinosaurs: 189-250. Boulder, CO: Westview Press.

Salgado, L. 1999. The macroevolution of the Diplodocimorpha (Dinosauria; Sauropoda): a developmental model. Ameghiniana 36: 203-216.

Salgado, L., and J.O. Calvo. 1992. Cranial osteology of Amargosaurus cazaui Salgado and Bonaparte (Sauropoda, Dicraeosauridae) from the Neocomian of Patagonia. Ameghiniana 29: 337-346.

Sampson, S.D., and L.M. Witmer. 2007. Craniofacial anatomy of Majungasaurus crenatissimus (Theropoda: Abelisauridae) from the Late Cretaceous of Madagascar. In: S.D. Sampson and D.W. Krause (editors), Majungasaurus crenatissimus (Theropoda: Abelisauridae) from the Late Cretaceous of Madagascar. Society of Vertebrate Paleontology Memoir 8: 225-253.

Sedlmayr, J.C. 2002. Anatomy, evolution, and functional significance of cephalic vasculature in Archosauria. Ph.D. dissertation, Ohio University, Athens, Ohio. 398 pp. 
Sereno, P.C., J.A. Wilson, L.M. Witmer, J.A. White, A. Maga, O. Ide, and T. Rowe. 2007. Structural extremes in a Cretaceous dinosaur. PloS ONE 2 (11): e1230, doi:10.1371/journal. pone. 0001230 .

Tidwell, V., and K. Carpenter. 2003. Braincase of an early Cretaceous titanosauriform sauropod from Texas. Journal of Vertebrate Paleontology 23: 176-180.

Upchurch, P. 1998. The phylogenetic relationships of sauropod dinosaurs. Zoological Journal of the Linnean Society 124: 43-103.

Upchurch, P., P.M. Barrett, and P. Dodson. 2004. Sauropoda. In D.B. Weishampel, P. Dodson and H. Osmólska (editors), The Dinosauria. 2nd ed: 259-322. Berkeley: University of California Press.

White, T.E. 1958. The braincase of Camarasaurus lentus (Marsh). Journal of Paleontology 32: 477-494.
Wilson, J.A. 2002. Sauropod dinosaur phylogeny critique and cladistic analysis. Zoological Journal of the Linnean Society 136: 217-276.

Wilson, J.A. 2005. Redescription of the Mongolian sauropod Nemegtosaurus mongoliensis Nowinski (Dinosauria: Saurischia) and comments on Late Cretaceous sauropod diversity. Journal of Systematic Palaeontology 3: 283-318.

Wilson, J.A., M.S. Malkani, and P.D. Gingerich. 2005. A sauropod braincase from the Pab Formation (Upper Cretaceous, Maastrichtian) of Balochistan, Pakistan. Gondwana Geological Magazine 8: 101-109.

Witmer, L.M., and R.C. Ridgely. 2009. New insights into the brain, braincase, and ear region of tyrannosaurs (Dinosauria, Theropoda), with implications for sensory organization and behavior. The Anatomical Record 292: 1266-1296.

Zheng, Z. 1991. Morphology of the braincase of Shunosaurus. Vertebrata Palasiatica 29: 108-118. 


Complete lists of all issues of the Novitates and the Bulletin are available at World Wide Web site http://library.amnh.org/pubs. Inquire about ordering printed copies via e-mail from scipubs@amnh.org or via standard mail from: American Museum of Natural History, Library-Scientific Publications, Central Park West at 79th St., New York, NY 10024. TEL: (212) 769-5545. FAX: (212) 769-5009.

(2) This paper meets the requirements of ANSI/NISO Z39.48-1992 (Permanence of Paper). 